\title{
Drivers of shortwave radiation fluxes in Arctic tundra across scales
}

\author{
Inge Juszak ${ }^{\mathrm{a}}$, Maitane Iturrate-Garcia ${ }^{\mathrm{a}}$, Jean-Philippe Gastellu-Etchegorry ${ }^{\mathrm{b}}$, \\ Michael E. Schaepman ${ }^{c}$, Trofim C. Maximov ${ }^{\mathrm{d}}$, Gabriela Schaepman-Strub ${ }^{\mathrm{a}}$ \\ ${ }^{a}$ Department of Evolutionary Biology and Environmental Studies, University of Zurich, \\ Winterthurerstrasse 190, 8057 Zurich, Switzerland \\ ${ }^{b}$ Centre d'Etudes Spatiales de la BIOsphère (CESBIO) - CNES, CNRS, IRD, Université de \\ Toulouse, 31401 Toulouse cedex 9, France \\ ${ }^{c}$ Remote Sensing Laboratories, University of Zurich, Winterthurerstrasse 190, 8057 Zurich, \\ Switzerland \\ ${ }^{d}$ Institute for Biological Problems of Cryolithozone, Siberian Branch of Russian Academy of \\ Sciences, 41 Lenin Avenue, Yakutsk, Yakutia 677980, Russian Federation
}

\begin{abstract}
Vegetation composition and water surface area are changing in many tundra regions due to climate warming, which is twice as strong in the Arctic as compared to the global mean. Such land cover changes feed back to climate and permafrost thaw through altering the surface energy budget. We quantified the influence of vegetation type, canopy characteristics, and patchiness on the tundra shortwave radiation components. We used in situ measurements and vegetation mapping to parametrise a 3D radiative transfer model (DART) for summer conditions at the Kytalyk test site in northeast Siberia. We analysed model results assessing the most important drivers of canopy albedo, transmittance, and absorptance of photosynthetically active radiation (PAR). Tundra albedo was strongly influenced by the fractional cover of water surfaces. Albedo decreased with increasing shrub cover. However, plant area index effects on albedo were not statistically significant. Canopy transmittance and PAR absorptance $\left(f_{\mathrm{APAR}}\right)$ were almost entirely controlled by plant area index at the landscape scale. Only about one half of the total plant area index consisted of green leaves, while wood and standing dead leaves contributed equally to the
\end{abstract}

\footnotetext{
${ }^{*}$ Corresponding author

Email address: inge.juszak@gmx.de (Inge Juszak)
}

Preprint submitted to Remote Sensing of Environment

February 16, 2017

(C) 2017. This manuscript version is made available under the Elsevier user license http://www.elsevier.com/open-access/userlicense/1.0/ 
other half. While spatial patterns and patch sizes of vegetation types and open water did not significantly influence the radiation budget at the landscape scale, it contributed to the large variability at the local scale. Such local variability of shortwave radiation may impact evapotranspiration and primary productivity at a range of scales. Therefore, the variation of radiation fluxes within single vegetation types potentially affects larger scale energy, water, and carbon fluxes. Keywords: 3D radiative transfer modelling; DART; In situ data; Vegetation type; Canopy properties; Albedo; Transmittance; Soil shading; fAPAR; Shrub; Sedge; Wood area index; Leaf angle distribution; Spatial heterogeneity

\section{1. Introduction}

2 Vegetation is an important part of the climate system as it reacts to climate 3 drivers and influences climate through changing Earth's surface properties. Arc4 tic greening, in particular the expansion of shrubs in tundra areas, is associated 5 with recent climate warming (Sturm et al., 2001; Myers-Smith et al., 2011; - Fraser et al., 2014). This greening directly affects the surface albedo, which 7 feeds back to climate through large scale warming (Chapin et al., 2005; Loranty 8 et al., 2011). Vegetation effects on permafrost thaw are more complex since - increased vegetation density not only leads to atmospheric warming but also 1o partly decouple permafrost from the atmosphere through insulation and soil 11 shading (Eugster et al., 2000; Walker et al., 2003; Cannone \& Guglielmin, 2009;

12 Briggs et al., 2014).

13 Encroachment of dense shrub canopies in previously graminoid or lichen dominated tundra reduces the average surface albedo and thus amplifies warming (Thompson et al., 2004; Beringer et al., 2005; Blok et al., 2011b). Furthermore, vegetation alters surface roughness and transpiration, which leads to changes in sensible and latent heat fluxes (Boudreau \& Rouse, 1995). Within the canopy, transpiration strongly depends on the light regime, in particular on the small scale heterogeneity (Song et al., 2009; He et al., 2014). Thus, resolving the shortwave energy budget helps understanding and modelling multiple land 
surface - climate feedback processes.

Permafrost is affected by vegetation cover in multiple ways. On one hand, vegetation shades the ground and thus reduces the amount of shortwave radiation that is absorbed by the soil (Benninghoff, 1952; Briggs et al., 2014). On the other hand, increasing vascular plant biomass reduces moss abundance through shading and litter production (van Wijk et al., 2003). Decreased moss abundance affects the soil heat flux as mosses can strongly insulate the soil from air temperature (Beringer et al., 2001; Blok et al., 2011a). Additional processes, such as trapping of snow by vegetation (Pomeroy et al., 2006), further influence the interaction between vegetation and permafrost thaw.

Tundra landscapes typically show small scale patterns, such as hummocks and polygons, which are associated with small water bodies and distinct vegetation types (Walker et al., 2008). Landscape variation and associated differences in soil moisture, nutrients, and $\mathrm{pH}$ can lead to different vegetation composition within meters (Walker et al., 2011; Muster et al., 2012). These patterns can either remain stable over decades (Gamon et al., 2012) or change rapidly for example due to permafrost degradation (Schuur et al., 2007). Large scale vegetation dynamics are also affected by wetland area and the water budget. While an increase in lake and wetland area has been observed in the Siberian tundra (Smith et al., 2005; Lin et al., 2012), the American Arctic shows a drying trend (Oechel et al., 2000; Carroll et al., 2011; Jones et al., 2011; Lin et al., 2012). Shrubs such as dwarf birch (Betula nana) profit from warming and fertilisation and become increasingly dominant (Bret-Harte et al., 2001).

The radiation budget of patterned tundra landscapes is expected to vary among and within vegetation types at fine scale (few centimetres) due to variations in canopy properties and edge effects. Currently, little is known about the radiation budget of such patterned landscapes, as satellite observations are too coarse to resolve the fine scale differences (Muster et al., 2012). The aim of this study is to analyse the shortwave radiation budget of heterogeneous tundra at the Kytalyk research site in northeast Siberia by using 3D radiative transfer modelling to resolve such fine scales. The focus is on increasing the understand- 
52

ing of drivers of albedo, transmittance, and absorbed radiation of the canopy from patch to landscape scale in summer. Using a 3D radiative transfer model, we provide insights into typical length scales of horizontal interaction between vegetation types and the influence of local land cover variability on the radiation budget at different scales. This is the first time that such a complex $3 \mathrm{D}$ radiation model has been parametrised with such high detailed structural and compositional measurements for the tundra.

\section{Methods}

\subsection{Field site}

Our field site is the Kytalyk nature reserve located in the Indigirka lowlands, northeast Siberia $\left(70.8^{\circ} \mathrm{N}, 147.5^{\circ} \mathrm{E}\right.$, Figure 1a). According to the circumpolar Arctic vegetation map, vegetation is classified as tussock sedge, dwarf shrub, moss tundra (Walker et al., 2005). Low shrub tundra (mainly Salix pulchra) occurs along rivers and at lake shores. The area is dominated by continuous permafrost of several hundred meters depth (Romanovskii et al., 2004) with an active layer thickness of 12 to $50 \mathrm{~cm}$ (Mi et al., 2014). The Kytalyk field site is described in more detail in van der Molen et al. (2007); Nauta et al. (2015) and Juszak et al. (2016). The size of our study area is $1.4 \mathrm{~km} \times 2 \mathrm{~km}$ (Figure $1 \mathrm{~b}$ ).

\subsection{Remote sensing data and products}

We used a ground referenced orthomosaic from a UAV (unmanned aerial vehicle, eBee, senseFly), acquired with digital cameras in four spectral bands (red, green, blue, and near infra-red (NIR)) to generate a NDVI (Normalized Difference Vegetation Index) map, a DSM (digital surface model), and a land cover map of dominant vegetation types. The map products have a spatial resolution of $5 \mathrm{~cm}$ and an extent of $1.4 \mathrm{~km} \times 2 \mathrm{~km}$.

\subsubsection{Orthomosaic, NDVI, and DSM}

The orthomosaic, which we obtained from the drone flights between 10 July and 10 August 2014, revealed some artefacts due to inhomogeneous illumination 

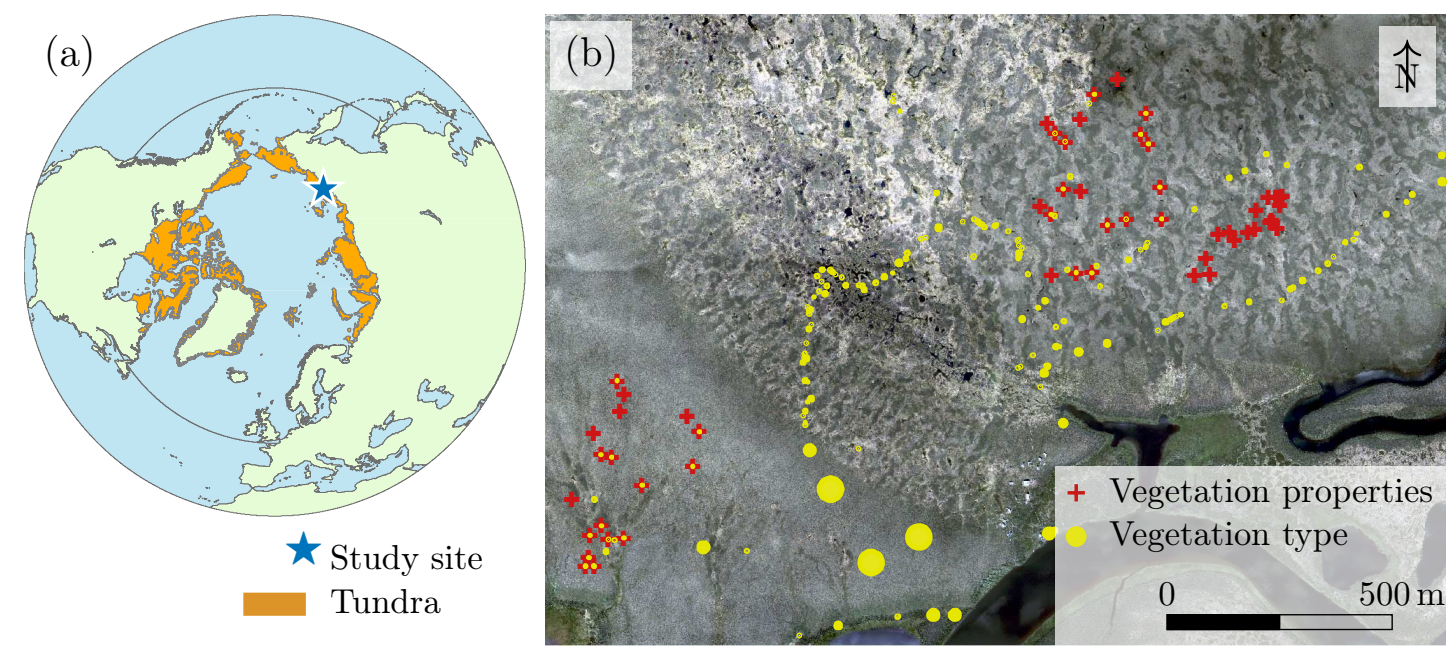

Figure 1: (a) Location of the study site in northeast Siberia (extent of Arctic tundra from Walker et al., 2005) and (b) orthomosaic of the study site including measurement locations of vegetation properties (red) and reference points for vegetation mapping (yellow, point size indicates represented area). during and between flights (Figure 2a). As these artefacts propagated to the estimated the NDVI from the red $\left(\rho_{\text {red }}\right)$ and NIR reflectance $\left(\rho_{N I R}\right)$ :

$$
\mathrm{NDVI}=\frac{\rho_{\mathrm{NIR}}-\rho_{\text {red }}}{\rho_{\mathrm{NIR}}+\rho_{\text {red }}}
$$

The DSM was generated from the point cloud which was created during the 85 image matching. Interpolation was performed using inverse distance weighting, 86 minimizing artefacts (Chaplot et al. (2006); Postflight Terra 3D, Version 4.0.83).

${ }_{87}$ The DSM represented a level between the top of canopy and the soil surface. The uncertainty is due to variability in canopy height and not related to topography. Since the vegetation was low $(<0.8 \mathrm{~m})$ and mostly sparse (average LAI of all vascular vegetation types $<1.5)$, some of the reference points for the DSM 91 may have been mapped at the soil surface. Thus we considered the DSM an 92 appropriate approximation of the ground elevation and used it as topographic 

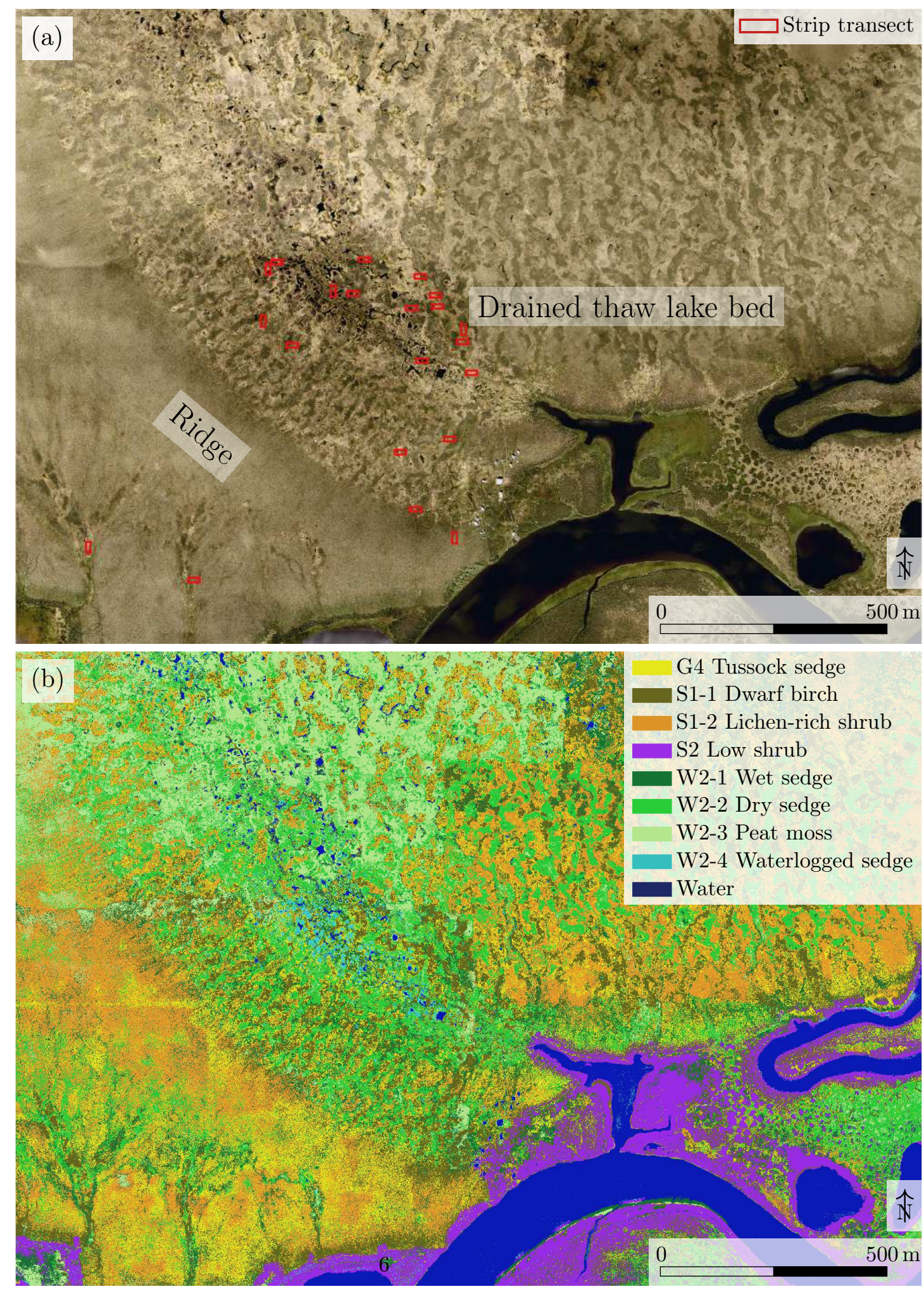

Figure 2: (a) Orthomosaic of the study area $(1.4 \mathrm{~km} \times 2 \mathrm{~km})$ including the locations of 21 strip transects and (b) vegetation map. 
input for modelling. The elevation difference between the river and the highest area of the ridge was about $23 \mathrm{~m}$. Fine scale drainage patterns could be detected in the DSM, for example in the area of the drained thaw lake bed. The DSM showed small scale height differences between the elevated shrub patches and wet sedge depressions.

\subsubsection{Vegetation map}

The reference points for training and validation of the vegetation map were acquired in the field $04-08$ July 2015 (Figure 1b). We defined eight vegetation types based on the class definition in the circumpolar Arctic vegetation map (Walker et al., 2005) which we split into sub-classes depending on species composition and canopy properties (Table 1). We performed supervised classification (ENVI, Version 5.2) as described in more detail in the appendix (Section A.1). To assess the classification accuracy, we took a random subset of the validation points with an equal amount of pixels per vegetation type (732 pixels). We computed the confusion matrix, user's accuracy, producer's accuracy, and the Kappa coefficient (Congalton, 1991).

\subsection{Vegetation characteristics used as model input variables and parameters}

The above vegetation classes were modelled in the $3 \mathrm{D}$ radiative transfer model DART based on vegetation type specific input variables and parameters. We use the term 'variable' for spatially varying model input data and the term 'parameter' for spatially invariant model input within a given vegetation type. The variables are green and standing dead leaf, and wood area index as well as canopy and standing dead leaf height.

For each vegetation type, we either measured the variables in the field during the peak growing season or compiled values from literature (see Section A.2 for details). We computed spatially varying green leaf area index (LAI) from NDVI following Street et al. (2007); Campioli et al. (2009):

$$
\mathrm{LAI}=a \cdot \exp (b \cdot \mathrm{NDVI})
$$


Table 1: Vegetation classes from the circumpolar Arctic vegetation map (Walker et al., 2005) and sub-classes as defined for this study; the background colours indicate the colour used for this vegetation type in maps and graphs.

\begin{tabular}{|c|c|c|}
\hline Class & $\begin{array}{l}\text { Sub- } \\
\text { class }\end{array}$ & Description \\
\hline G4 & & $\begin{array}{l}\text { Tussock sedge (Eriophorum vaginatum), dwarf shrub, moss } \\
\text { tundra }\end{array}$ \\
\hline \multirow[t]{3}{*}{ S1 } & & Erect dwarf shrub tundra $(<40 \mathrm{~cm})$ \\
\hline & S1-1 & Dwarf birch (Betula nana) dominated \\
\hline & $\mathrm{S} 1-2$ & Lichen-rich shrub, Vaccinium spp. dominated \\
\hline $\mathrm{S} 2$ & & Low shrub tundra $(>40 \mathrm{~cm}$, Salix pulchra) \\
\hline \multirow[t]{5}{*}{$\mathrm{W} 2$} & & Sedge, moss, dwarf shrub $(<40 \mathrm{~cm})$ wetland \\
\hline & W2-1 & Wet sedge, Eriophorum angustifolium dominated, dense, green \\
\hline & W2-2 & $\begin{array}{l}\text { Dry sedge, Eriophorum angustifolium and Sphagnum spp. } \\
\text { dominated }\end{array}$ \\
\hline & W2-3 & Peat moss (Sphagnum spp.) dominated \\
\hline & W2-4 & $\begin{array}{l}\text { Waterlogged sedge, Carex spp. dominated, few standing dead } \\
\text { leaves }\end{array}$ \\
\hline Water & & Open water \\
\hline
\end{tabular}

We obtained $a$ and $b$ by fitting the exponential relationship on five quantiles $(0.05,0.25,0.50,0.75$, and 0.95$)$ of the in situ LAI measurements and UAVderived NDVI of all pixels within the vegetation type in question (see Appendix, Table A1).

We used linear regressions with observed LAI to spatially extrapolate wood and standing dead leaf area index as well as canopy and standing dead leaf height:

$$
x=p \cdot \mathrm{LAI}+q
$$

where $x$ is the extrapolated variable and $p$ and $q$ represent vegetation type specific parameters (see Appendix, Table A1). The average and standard deviation of all variables for each vegetation type were computed for the entire strip 
transects (Table 2).

Table 2: Summary of canopy properties used as model input; for plant area index and canopy height mean \pm standard deviation of all cells are provided; the species column indicates which species was used for measuring the input parameters inclination angle and optical properties.

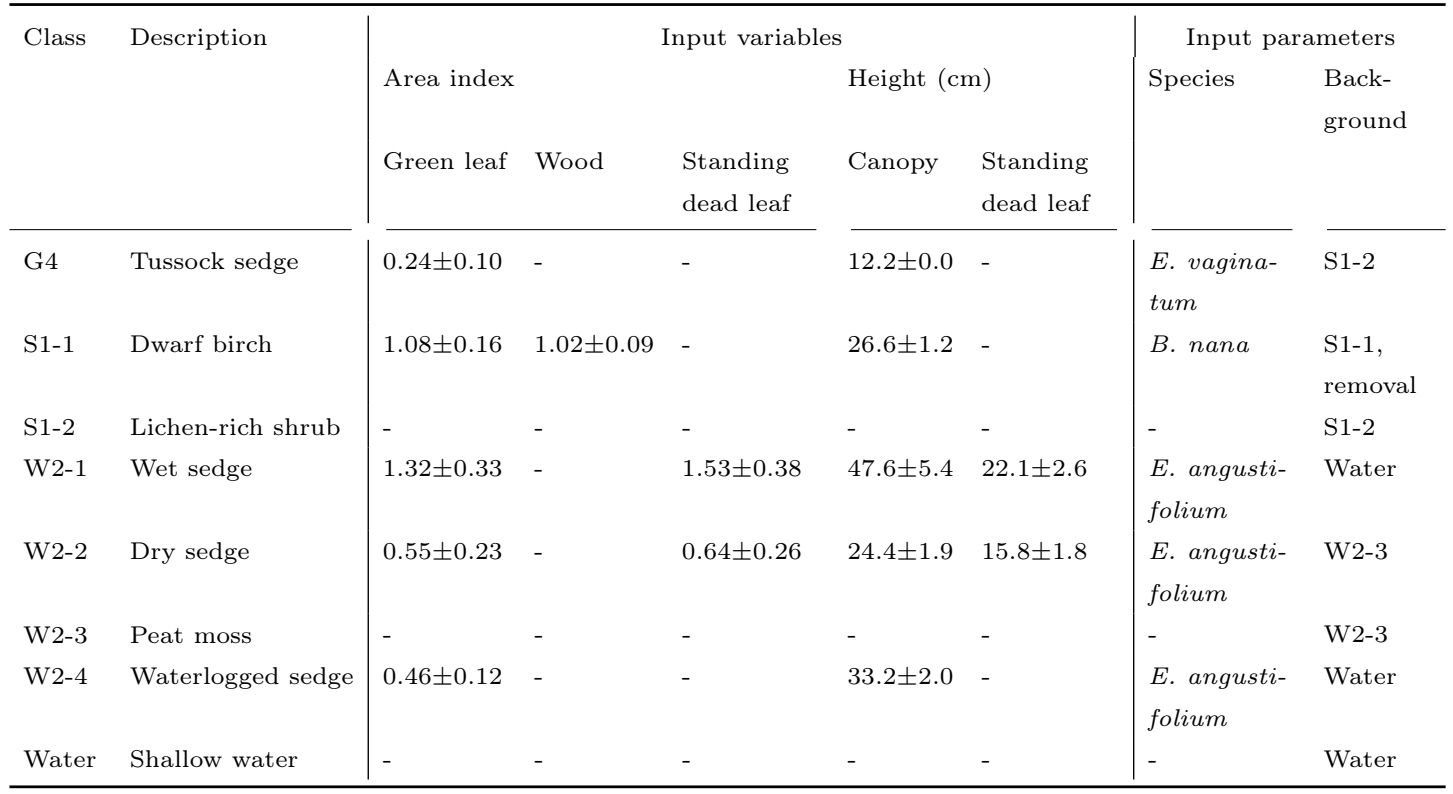

$131 \quad$ An example of all input variables for one strip transect is shown in Figure 3.

132 The LAI included Betula and Salix shrubs as well as Eriophorum and Carex

133 sedges but neither dwarf shrubs $<5 \mathrm{~cm}$ such as Vaccinium spp. and Ledum

${ }_{134}$ palustre, nor grasses nor forbs. The LAI only made up for about half of the total plant area index (PAI) with about one fourth being wood and one fourth standing dead leaves. The average canopy height was $25.3 \mathrm{~cm}$ in the study area. 

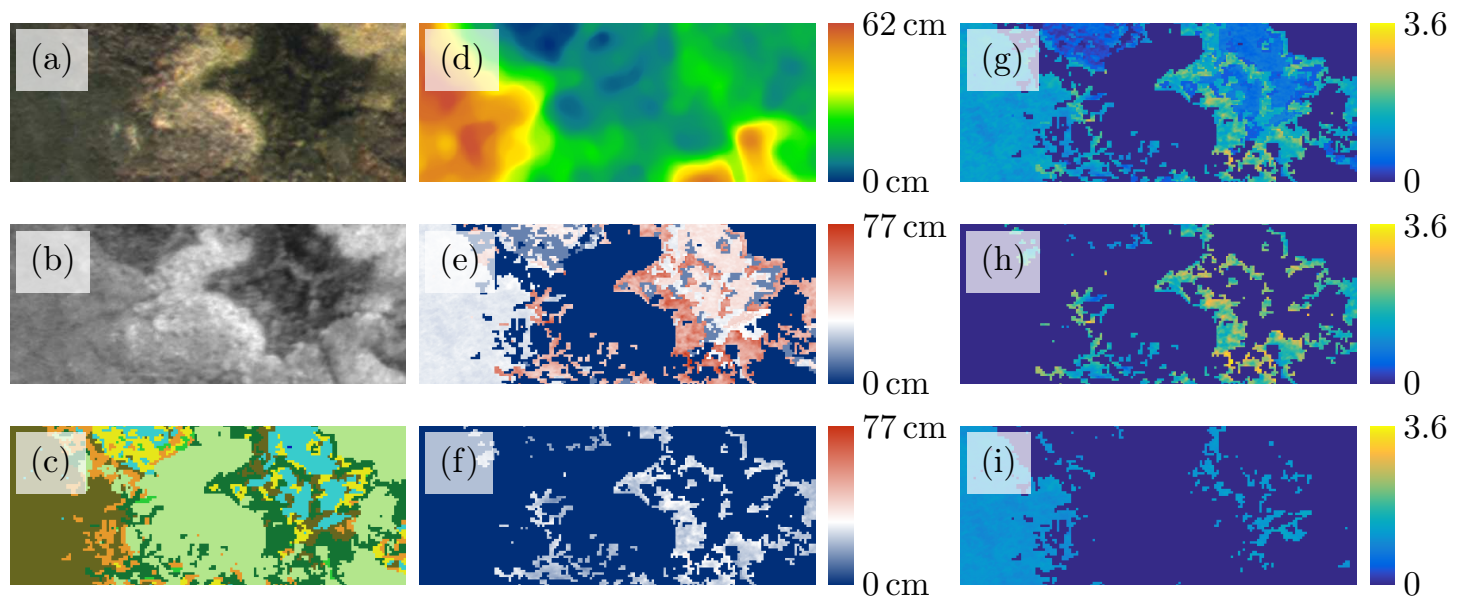

G4

S1-1

S1-2

W2-1

W2-2

W2-3

W2-4

Water

Figure 3: Input variables for one strip transect $(10 \mathrm{~m} \times 25 \mathrm{~m})$ as an example; (a) RGB image, (b) near infra-red image, (c) vegetation map, (d) digital surface model, (e) canopy height, (f) standing dead leaf height, (g) green leaf area index, (h) standing dead leaf area index, and (i) wood area index. 
Input parameters were the angular distribution and the optical properties of green leaves, standing dead leaves, and wood and the background reflectance. We measured the input parameters during the peak growing season. We estimated the leaf angle distribution with the method by Pisek et al. (2011) and applied a correction for green and standing dead sedge leaves and wood (Appendix, Figure A2). The correction was necessary because it was not possible to identify wood or sedge leaves that were perpendicular to the image plane (see Section A.3 for details).

Optical properties of green and standing dead leaves and wood were measured in the field with a dual integrating sphere design for reflected and transmitted light in the spectral range from 400-950 nm (Jaz \& SpectroClip, Ocean Optics). From 950-2500 nm, we used dwarf birch (Betula nana) optical properties measured at the same field site for leaves, standing dead leaves, and wood of all species (Fieldspec4, ASD Inc., Juszak et al., 2014, Appendix, Figure A3a).

We measured spectral background reflectance on canopies lower than $5 \mathrm{~cm}$ and on shallow water 13 - 23 July 2008 (Fieldspec4, ASD Inc.). Reflectance measurements of Vaccinium dominated lichen-rich shrub communities (S1-2) were selected as background for tussock sedge tundra as the species composition was similar. Peat moss (W2-3) dominated below dry sedge vegetation and was thus used as background for modelling. For wet and waterlogged sedges we used measurements of shallow water as background (Table 2). Additionally, we used the background reflectance below dwarf birch (S1-1) after removing the shrubs (see Juszak et al., 2014). At least four measurements were averaged per background type (Appendix, Figure A3b).

\subsection{Radiation budget simulations with DART}

We simulated the radiation budget using the DART 3D radiative transfer model (Gastellu-Etchegorry et al., 1996; Grau \& Gastellu-Etchegorry, 2013; Gastellu-Etchegorry et al., 2015, Version 5.6.1). The DART model tracks radiation fluxes within the 3D canopy including multiple reflections and mutual shading (Schneider et al., 2014). This model has been applied and validated 
extensively, for example for forest canopies (Malenovský et al., 2008; Schneider et al., 2014), crops (Duthoit et al., 2008), and tundra dwarf shrubs (Juszak et al., 2014). The DART model formed part of the radiation transfer model intercomparison (RAMI) (Pinty et al., 2001; Widlowski et al., 2015).

\subsubsection{Model configuration}

We parametrised the DART radiative transfer model for 21 strip transects and 9 homogeneous cover types for one point in time in the peak growing season. Vegetation was parametrised in a voxel grid filled with turbid media scatterers (Schneider et al., 2014). Three types of turbid media were simultaneously considered: green leaves, dead leaves, and wood. Each turbid medium was simulated as a vertically homogeneous column within its respective height. However, standing dead leaves of wet and dry sedges were implemented with a lower height than green leaves (Table 2). Thus, voxels at low height were dominated by standing dead leaves and higher voxels by green leaves in these two vegetation classes. For the strip transects, we used the DSM as topography while we simulated the homogeneous cover types without topography (Table 3).

We simulated shortwave radiation fluxes for MODIS bands 1 to 7 (Table 3 ) and derived broadband shortwave quantities (full shortwave albedo and full shortwave transmittance) from a linear combination of bands with coefficients by Liang et al. (1999). Additionally, we simulated broadband photosynthetically active radiation (PAR) to assess the fraction of PAR which is absorbed by the canopy $\left(f_{\mathrm{APAR}}\right)$ and to compare the results with the PAR conversion from three MODIS bands by Liang et al. (1999). In the simulations, the illumination was defined by the total irradiance and the fraction of diffuse light for each spectral band (Table 3). The spectral irradiance was defined as the reflectance of a Spectralon panel measured around solar noon on 11/07/2012 under clear sky conditions using a spectrometer (Fieldspec4, ASD Inc.). All spectrometer measurements within a MODIS full width at half maximum band width or the PAR range were averaged to obtain the irradiance within the band in question. The diffuse fraction in the PAR range was obtained from field measurements 
197

Table 3: General model configuration and spectral bands with respective irradiance and diffuse fraction (SKYL); the spectral bands represent the full width at half maximum (FWHM) of the MODIS instrument.

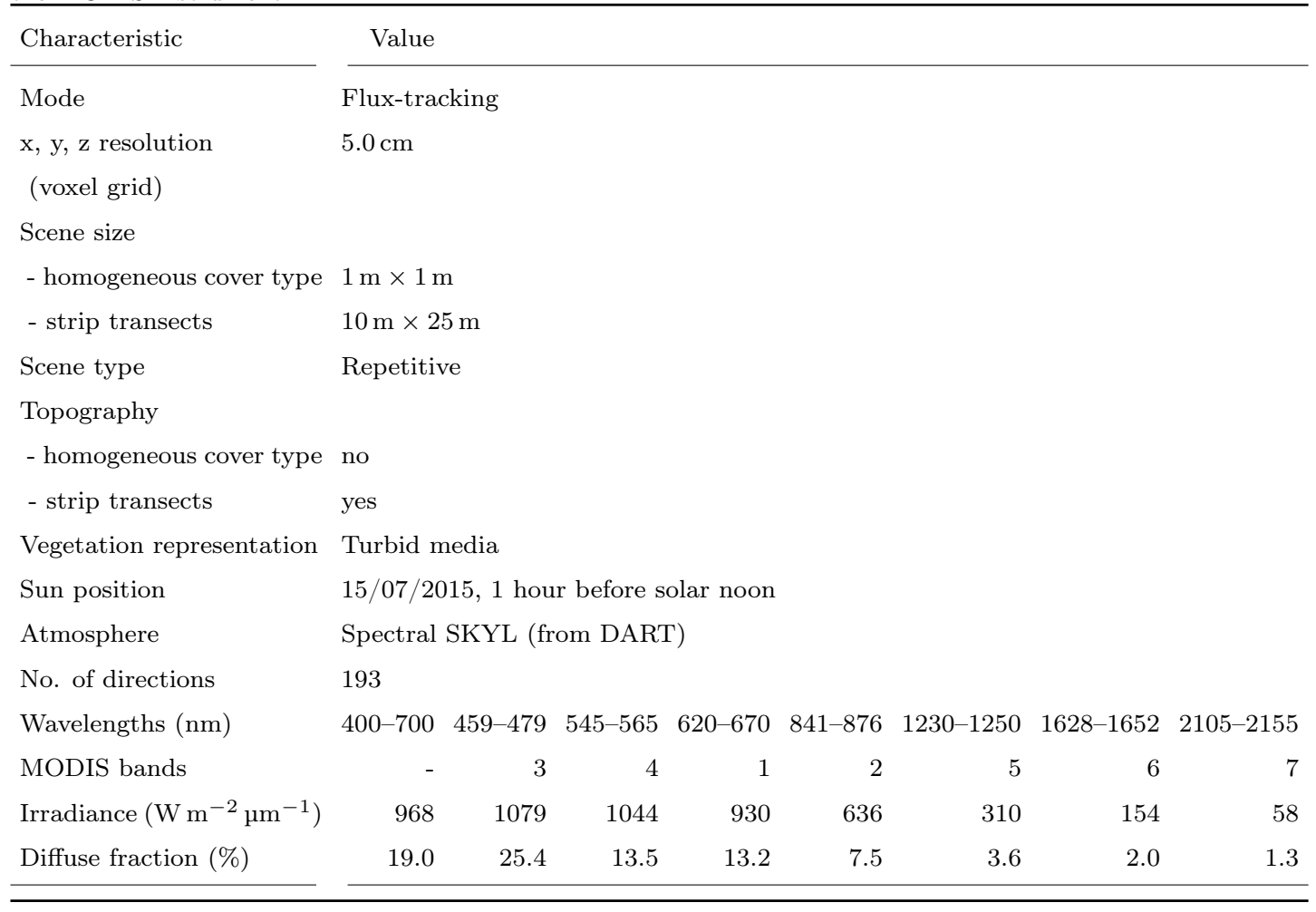




\subsubsection{Model outputs}

We analysed three major model outputs. The first output was the shortwave albedo one metre above the soil surface, which we converted from spectral to shortwave albedo (Liang et al., 1999). The second output was shortwave irradiance at the soil surface divided by above canopy shortwave irradiance. We call this variable 'transmittance', which equals to ' 1 - soil shading' (Benninghoff, 1952). Canopy transmittance influences soil heat flux and permafrost thaw (Briggs et al., 2014). We considered the fraction of photosynthetically active radiation absorbed by the canopy $\left(\mathrm{f}_{\mathrm{APAR}}\right)$ as the third output. We defined the canopy as vascular vegetation parametrised in the radiative transfer model. Therefore, mosses, lichen and vascular plants lower than $5 \mathrm{~cm}$, which we treated as background, did not contribute to $\mathrm{f}_{\mathrm{APAR}}$ and soil shading. Although $\mathrm{f}_{\mathrm{APAR}}$ is closely linked to canopy transmittance, it provides additional information as it is associated with photosynthesis and thus the carbon cycle (Ruimy et al., 1994; Huemmrich et al., 2010). Before analysing the model output, we removed $2 \mathrm{~m}$ borders on all sides of the strip transects to eliminate edge effects. Thus the remaining strip transect size was $6 \mathrm{~m} \times 21 \mathrm{~m}(120 \times 420$ pixels $)$.

\subsubsection{Selection of subsets for modelling}

Model simulations were done with two different land cover complexities. First, we simulated homogeneous land cover types without topography and second, we simulated the radiation budget of 21 strip transects including heterogeneous tundra vegetation. We refer to this complex 3D simulation at the landscape scale as direct 3D simulations. For both complexities, we used the same average canopy variables and parameters (Table 2).

To quantify the shortwave radiation budget of heterogeneous tundra, we selected subsets of the study area on the vegetation map (Figure $2 b$ ). We chose strip transects within a single flight area (flown twice, 23 and 31 July 2014) because of artefacts due to inhomogeneous illumination (Figure 2a). Due to the low vegetation height of the tundra in our study area (Table 2) and the small scale spatial variability of vegetation type, we selected 21 strip transects 
of $10 \mathrm{~m} \times 25 \mathrm{~m}$ representative of the landscape scale. Each strip transect represented a transition between dwarf birch dominated vegetation (S1-1) and other vegetation types or water (Figure 4). As low shrub tundra (S2) was restricted to lake and river banks, we did not choose strip transects in this vegetation type. The remaining six vegetation types and water were each dominating three strip transects. Additionally, all vegetation types were represented in smaller fractions also in the other strip transects. The patch size distribution differed among the strip transects.

We computed explanatory variables at two different levels, for the whole strip transects and for each vegetation patch. For the strip transects, we used the explanatory variables (I) average PAI including green leaves, standing dead leaves, and wood, (II) fractional cover of each vegetation type, and (III) mean characteristic length, which we defined as mean ratio of patch area to patch perimeter. We used the characteristic length as proxy for edge effects, which are more important for strip transects with a small mean characteristic length. The radiation budget of a single patch is influenced by its vegetation type, PAI, canopy height, neighbouring vegetation, and topography. Topography influences the radiation budget more at the patch scale than at the transect scale, because the strip transects are mostly flat on average while mounds and tussocks influence local slope and exposition. We assessed the influence of local variability and edge effects using the characteristic length of the single vegetation patches in relation with their radiation budget. 


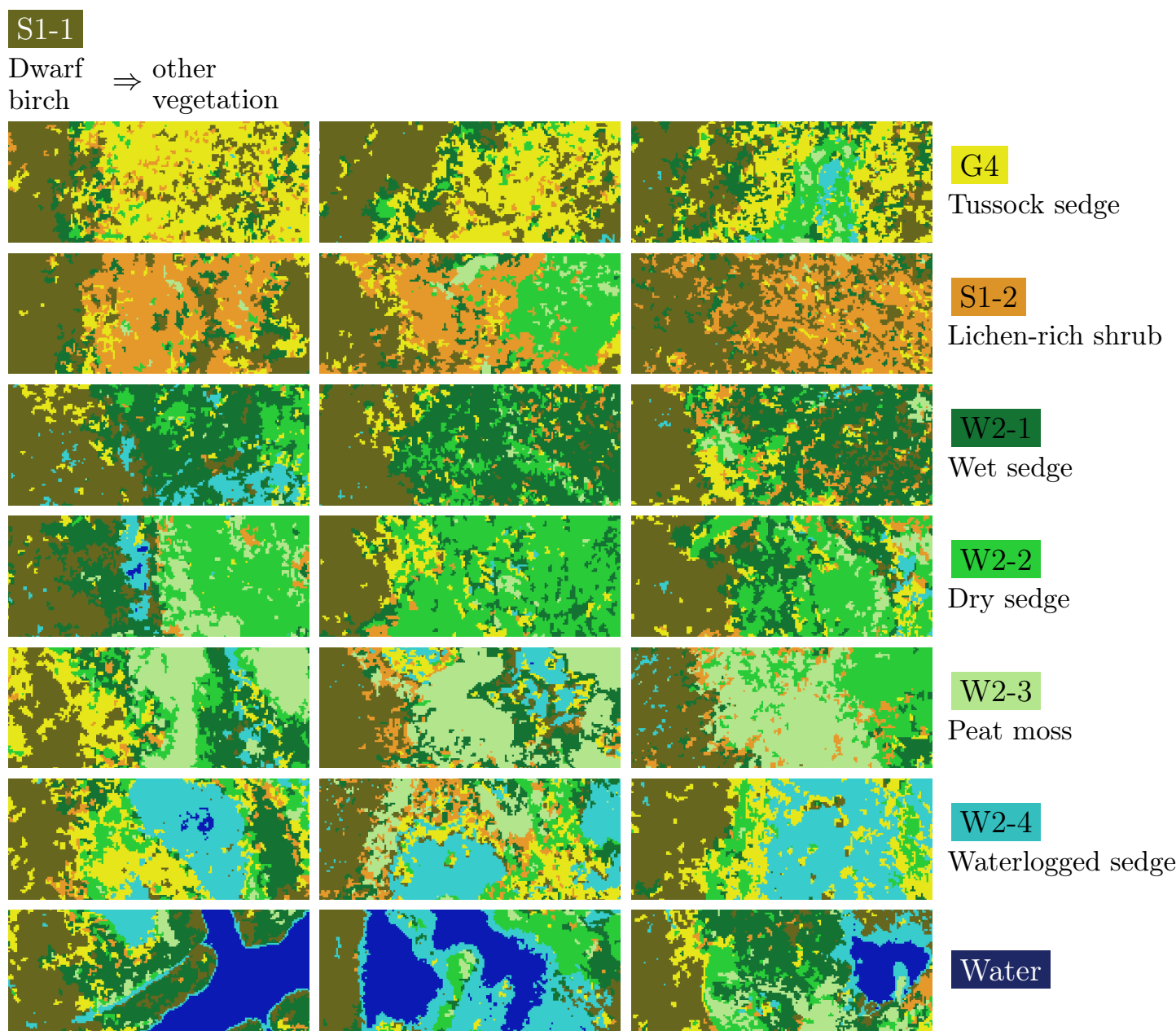

Figure 4: Vegetation maps of 21 strip transects $(10 \mathrm{~m} \times 25 \mathrm{~m})$; the rows represent different major vegetation types sorted by the mean characteristic length of the major type with simple polygons on the left and more complex polygons on the right. 


\subsection{Weighted averages}

In addition to the direct 3D radiative transfer simulations, we estimated the radiation budget of each strip transect using weighted averages. The weighted averages were calculated using the radiation budget for each land-cover type, weighted by the fraction of the cover types within each strip transect. The weighted averages were computed in two steps. In a first step, we computed the $3 \mathrm{D}$ radiation budget of homogeneous vegetation types with DART using the same mean vegetation type specific variables as for the strip transect simulations in a small and repetitive scene (Table 2). DART was configured in the same way as for the strip transects, but the scene was smaller and did not include topography (Table 3). In a second step, we computed the average albedo, transmittance, and $\mathrm{f}_{\mathrm{APAR}}$ weighted by land cover type fraction for each strip transect. Thus the weighted averages are an easy and fast method to estimate radiation quantities, which does not take into account the spatial distribution of the land cover types or any other interactions between them.

\subsection{Statistical analysis}

We estimated the importance of different strip transect characteristics on the mean radiation budget using an analysis of variance (ANOVA, f-test) ( $\mathrm{R}$ Core Team, 2015, Version 3.2.3). The response variables were strip transect albedo, transmittance, and $f_{A P A R}$. The explanatory variables of each strip transect were the fraction of shrub cover (S1-1), the combined fraction of water and waterlogged sedges (W2-4), mean PAI, and mean patch characteristic length. We did a 4-way ANOVA per response variable without taking into account interactions between explanatory variables. Our model first accounted for the explanatory variable with the highest correlation coefficient with the response. We changed the order of the other three response variables in the model to assess the robustness of the model results and possible relationships among the explanatory variables. The radiation budget simulated directly with the $3 \mathrm{D}$ radiative transfer model was compared with the weighted averages using a paired t-test (R Core Team, 2015, Version 3.2.3). 


\section{Results}

\subsection{Vegetation map}

Betula dwarf shrubs (S1-1) and Salix low shrubs (S2) covered about $20 \%$ of the landscape, another $39 \%$ was covered by densely vegetated wetlands (W2-1, W2-2, W2-3) and $8 \%$ by water bodies and waterlogged sedges (W2-4). The remaining area was classified as either tussock sedge (G4) or lichen-rich dwarf shrub tundra (S1-2). The Kappa coefficient of the vegetation classification was 0.44, the overall accuracy was 50\%. The confusion matrix (Table 4) indicates that tussock tundra (G4) was similar to lichen-rich shrub tundra (S1-2). Therefore, large parts of the tussock tundra in the area of the ridge were misclassified as S1-2 (Figure 2b). Furthermore, dry sedges (W2-2) and peat moss tundra (W2-3) resembled each other in appearance and (shallow) water was often classified as waterlogged sedges (W2-4).

Table 4: Confusion matrix of the vegetation map calculated from a random subset of the validation data with an equal number of validation pixels per class.

\begin{tabular}{|c|c|c|c|c|c|c|c|c|c|c|c|}
\hline & & & & & & Lap & & & & & Producer's \\
\hline & & G4 & $\mathrm{S} 1-1$ & $\mathrm{~S} 1-2$ & $\mathrm{~S} 2$ & W2-1 & W2-2 & W2-3 & W2-4 & Water & accuracy (\%) \\
\hline & G4 & 160 & 41 & 468 & 0 & 47 & 6 & 10 & 0 & 0 & 22 \\
\hline & $\mathrm{S} 1-1$ & 133 & 297 & 240 & 0 & 43 & 15 & 0 & 4 & 0 & 41 \\
\hline & $\mathrm{S} 1-2$ & 54 & 43 & 483 & 0 & 99 & 37 & 16 & 0 & 0 & 66 \\
\hline$\underset{7}{\vec{t}}$ & $\mathrm{~S} 2$ & 1 & 27 & 2 & 652 & 19 & 2 & 0 & 28 & 1 & 89 \\
\hline T & W2-1 & 18 & 104 & 14 & 0 & 338 & 188 & 49 & 21 & 0 & 46 \\
\hline $0_{0}^{0}$ & W2-2 & 18 & 0 & 162 & 0 & 17 & 407 & 128 & 0 & 0 & 56 \\
\hline & W2-3 & 0 & 0 & 78 & 0 & 0 & 424 & 230 & 0 & 0 & 31 \\
\hline & $\mathrm{W} 2-4$ & 19 & 27 & 0 & 0 & 10 & 3 & 0 & 654 & 19 & 89 \\
\hline & Water & 0 & 0 & 4 & 0 & 15 & 1 & 0 & 629 & 83 & 11 \\
\hline & User's & & & & & & & & & & Overall \\
\hline & $\begin{array}{l}\text { accuracy } \\
(\%)\end{array}$ & 40 & 55 & 33 & 100 & 57 & 38 & 53 & 49 & 81 & $50 \%$ \\
\hline
\end{tabular}




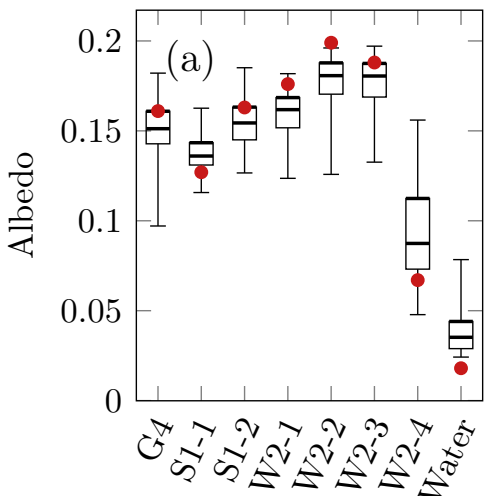

Vegetation type

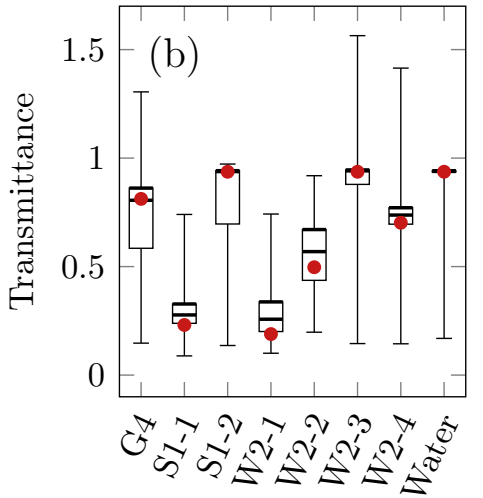

Vegetation type

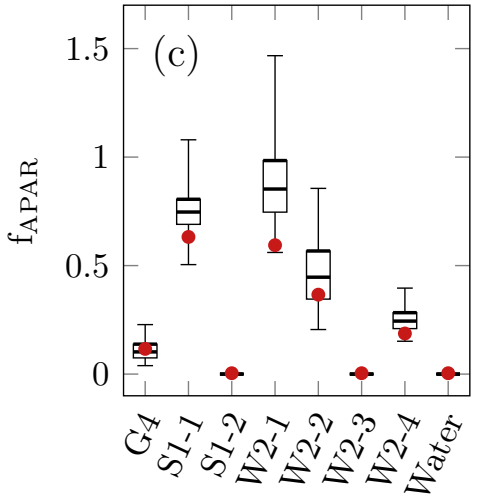

Vegetation type

Figure 5: Modelled radiation budget components for all cells of all strip transects, (a) albedo, (b) transmittance, and (c) fraction of PAR absorbed by the canopy $\left(\mathrm{f}_{\mathrm{APAR}}\right)$; the boxes indicate the $0.25,0.5$, and 0.75 quantiles, the whiskers are the 0.02 and 0.98 quantiles; red dots indicate the modelling results using homogeneous cover types.

At the patch scale, albedo was not related to transmittance $(R=0.00)$ or $\mathrm{f}_{\mathrm{APAR}}(R=-0.05$, results not shown $)$. While transmittance and $\mathrm{f}_{\mathrm{APAR}}$ were highly negatively correlated at the landscape scale, the negative correlation between them was reduced to $R=-0.43$ at the patch scale. Patch $\mathrm{f}_{\mathrm{APAR}}$ was highly positively correlated with PAI $(R=0.96)$. However, the correlation 
327

328

between patch transmittance and PAI was less strongly negative $(R=-0.57)$ than at the landscape scale.

The larger the patch area was in relation to its perimeter, the smaller was the influence of bordering vegetation, LAI variation, and topography on the patch average albedo, transmittance, and $\mathrm{f}_{\mathrm{APAR}}$ (Figure 6). The characteristic length at which a radiation budget component is independent of edge effects can be estimated from the convergence of an upper and a lower hull curve. Depending on the vegetation type, variation in patch albedo and $\mathrm{f}_{\mathrm{APAR}}$ was small for patches with characteristic lengths above $0.5 \mathrm{~m}$ on average, while patch transmittance was variable until $0.7 \mathrm{~m}$. However, the variability among vegetation types was large (Figure 6). Thus, the characteristic length scale depended on the radiation quantity in question and on vegetation type. In terms of patch area, converging hull functions indicated small edge effects for patches of $7 \mathrm{~m}^{2}$ or more for albedo and $\mathrm{f}_{\mathrm{APAR}}$ and $10 \mathrm{~m}^{2}$ area for transmittance, respectively. Although only $2 \%$ of the patches were larger than $7 \mathrm{~m}^{2}$, such large patches represented $65 \%$ of the total area in the modelled strip transects. 


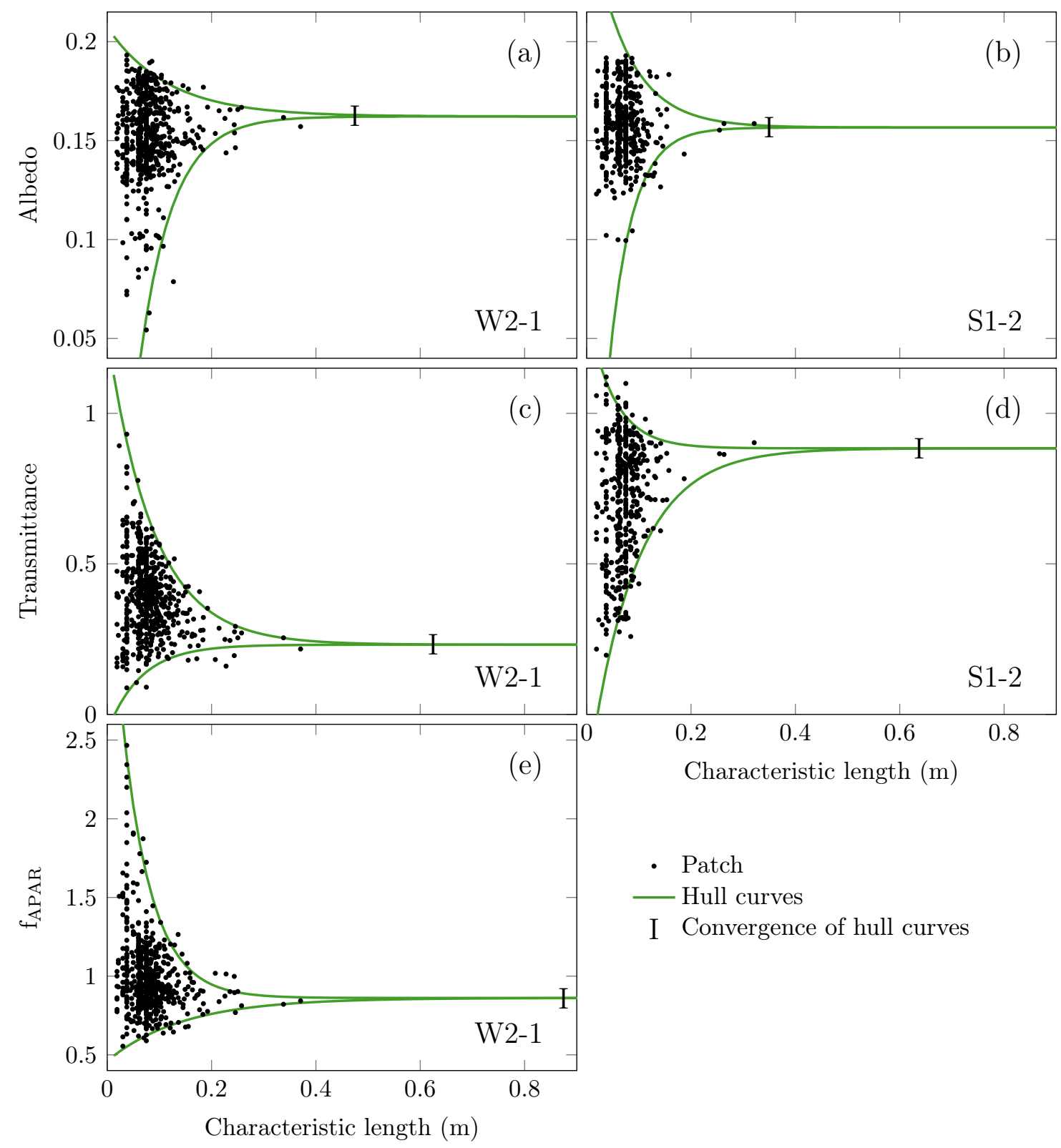

Figure 6: Mean patch (a,b) albedo, (c,d) transmittance, and (e) fraction of PAR absorbed by the canopy $\left(f_{A P A R}\right)$ as a function of characteristic length (patch area to perimeter ratio) for wet sedges (W2-1) and lichen-rich shrubs (S1-2); one point per patch; the green lines represent exponential curves fitted to the outer points as hull curves and converging at the indicated point (threshold $=0.001)$. 


\subsection{Drivers of the radiation budget at the landscape scale}

We compared modelled radiation budgets of different strip transects to estimate the importance of different landscape elements. Strip transect albedo was strongly negatively related with water fractional cover (including waterlogged sedges (W2-4), Pearson correlation $R=-0.91$, Figure 7b). Shrub cover significantly affected the albedo when the statistical model accounted for the water effect first (Table 5). Higher shrub cover was associated with lower albedo values. If all data were taken into account, the relationship between shrub cover and albedo was concealed by the strong influence of water cover $(R=0.19$, Figure 7a). However, excluding the strip transects with more than $20 \%$ water cover (coloured red in Figure 7a), the relationship was more clear $(R=-0.91)$. After accounting for water cover, neither PAI nor the average patch characteristic length were significantly related to strip transect albedo, even if the model did not account for shrub cover first. The correlation between each pair of explanatory variables was less than $|R|=0.55$. Landscape albedo was only weakly related with transmittance $(R=-0.40)$ and $\mathrm{f}_{\mathrm{APAR}}(R=0.38)$.

Table 5: The effect of strip transect characteristics on simulated albedo and transmittance expressed as ANOVA results; water cover includes waterlogged sedges (W2-4). Each characteristic takes one of 20 degrees of freedom (df); please note the different variable order; *** $P \leq 0.001 ; * * P \leq 0.01 ;$ ns: not significant.

\begin{tabular}{|c|c|c|c|}
\hline & df & $F$ & $P$ \\
\hline \multicolumn{4}{|l|}{ Albedo } \\
\hline Water cover & 1 & 277.90 & $* * *$ \\
\hline Shrub cover & 1 & 38.15 & $* * *$ \\
\hline Plant area index & 1 & 0.01 & ns \\
\hline Characteristic length & 1 & 0.89 & ns \\
\hline \multicolumn{4}{|l|}{ Transmittance } \\
\hline Plant area index & 1 & 617.38 & $* * *$ \\
\hline Shrub cover & 1 & 9.71 & $* *$ \\
\hline Water cover & 1 & 2.13 & ns \\
\hline Characteristic length & 1 & 0.91 & ns \\
\hline
\end{tabular}


345 Modelled strip transect $\mathrm{f}_{\mathrm{APAR}}$ and shortwave transmittance were strongly 346 negatively correlated $(R=-0.99)$. PAI strongly reduced canopy transmittance ${ }_{347}(R=-0.98$, Figure $7 \mathrm{~g})$ and increased $\mathrm{f}_{\mathrm{APAR}}(R=0.98$, Figure $7 \mathrm{k})$. The 348 second most important driver of both variables was shrub cover $(R=-0.34$ 349 and $R=0.28$ for transmittance and $\mathrm{f}_{\mathrm{APAR}}$, respectively, Figure 7e, i), which 350 significantly influenced transmittance but not $\mathrm{f}_{\text {APAR }}$ when PAI was accounted 351 for (Table 5). Water cover and average patch characteristic length did not 352 significantly affect transmittance and $\mathrm{f}_{\mathrm{APAR}}$. 


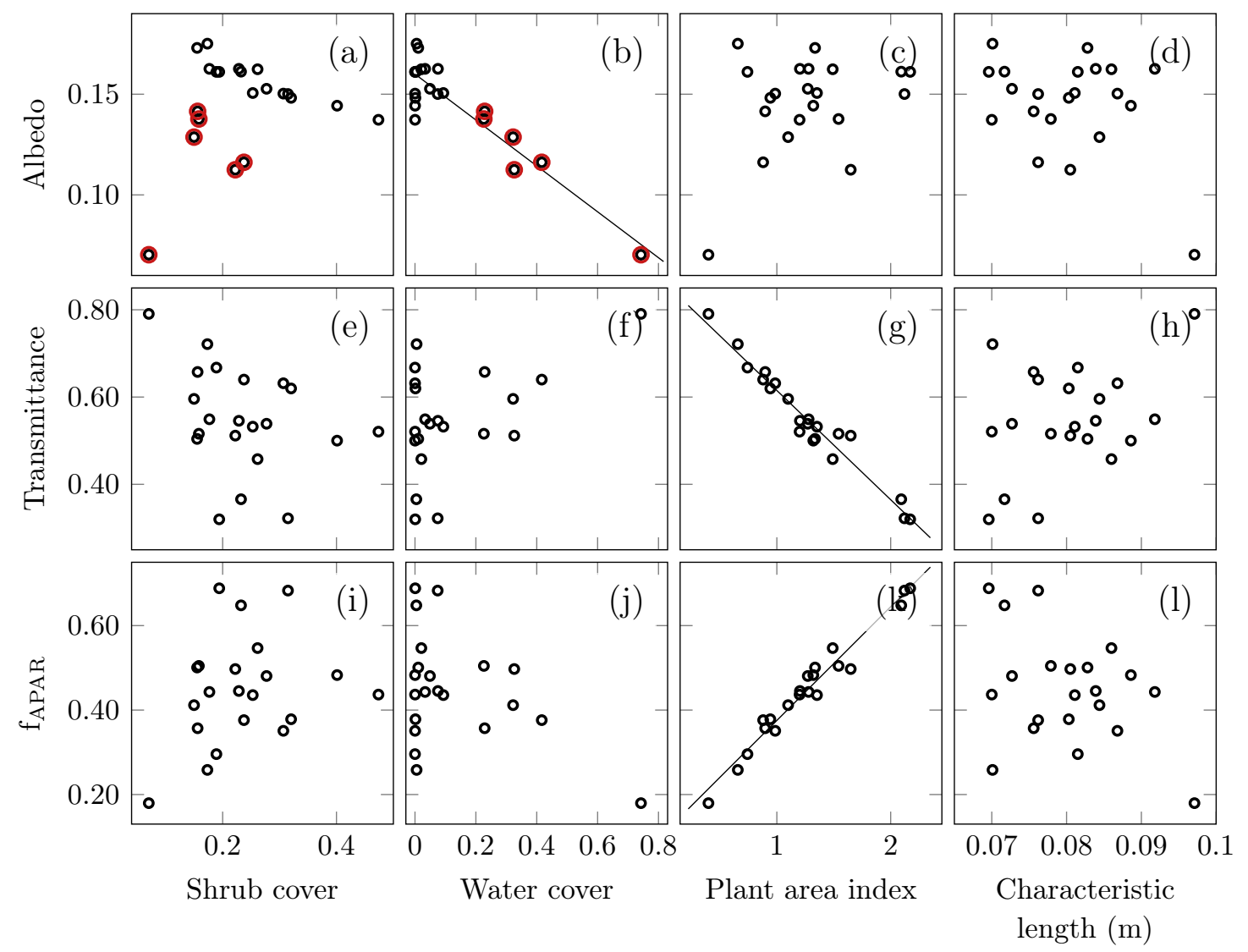

Figure 7: Modelled DART strip transect (a-d) albedo, $(\mathrm{e}-\mathrm{h})$ transmittance, and (i-l) fraction of PAR absorbed by the canopy ( $\left.f_{\text {APAR }}\right)$ as a function of (a, e, i) shrub fractional cover (S1-1), $(b, f, j)$ combined fractional cover of water and waterlogged sedges (W2-4), (c, g, k) plant area index, and $(\mathrm{d}, \mathrm{h}, \mathrm{l})$ average characteristic length; regression lines are included for data with $|R|>0.5$; in (a) and (b) strip transects with water cover above $20 \%$ are highlighted in red. 


\subsection{Influence of spatial distribution and interaction of land cover types}

We analysed results of direct 3D radiative transfer simulations as compared to a weighted average of the radiation budget with given fractional cover per vegetation type and average type properties. While the direct $3 \mathrm{D}$ simulations included the spatial distribution and interactions between land cover types, such effects were not accounted for in the weighted average approach. Using the 3D model, strip transect albedo values were significantly lower than the weighted average $(p<0.001$, Figure 8a). On average, the albedo reduction when using the direct $3 \mathrm{D}$ approach was 0.004 , corresponding to $3 \%$ of the average albedo, and the maximum absolute difference was 0.01 .

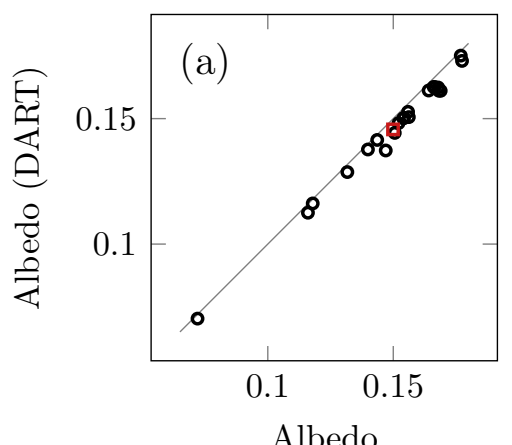

Albedo

(weighted average)
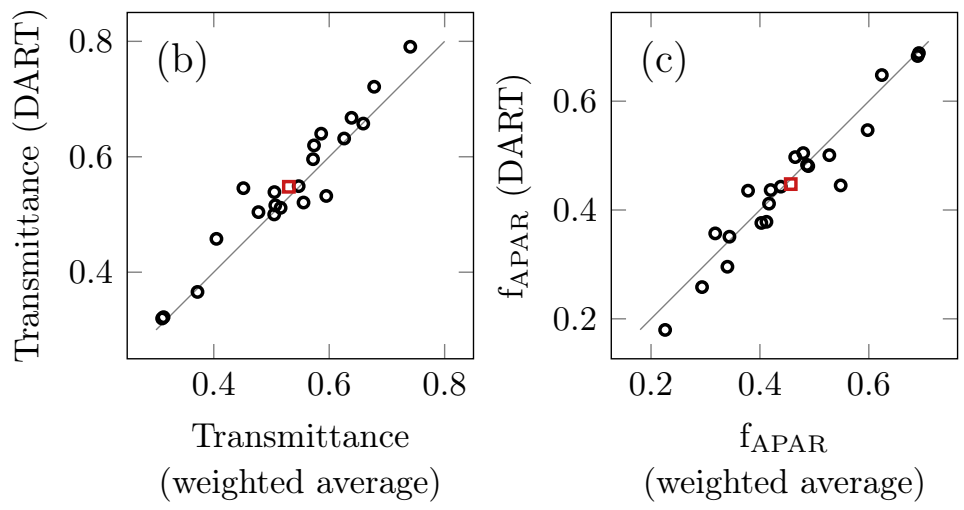

Figure 8: (a) Albedo, (b) transmittance, and (c) fraction of PAR absorbed by the canopy $\left(\mathrm{f}_{\text {APAR }}\right)$ modelled for each strip transect with DART and computed with weighted averages of the radiation quantities of land cover types occurring in the strip transect; each point represents one strip transect, the mean of all strip transects is the red square, the line represents a 1:1 relationship.

Canopy transmittance was on average $3 \%$ higher in the direct 3D model results as compared to the weighted average (Figure 8b). However, this was not the case for all strip transects. For single strip transects, the absolute transmittance difference was between -0.06 and 0.09 . The $3 \mathrm{D}$ model results were significantly different from the weighted averages $(p<0.05)$. Transmittance modelled with the 3D approach was generally higher than with the weighted 
average for strip transects with low PAI and low shrub cover (results not shown).

As described above, $\mathrm{f}_{\mathrm{APAR}}$ was strongly negatively related with transmittance. Consequently, $\mathrm{f}_{\mathrm{APAR}}$ was slightly reduced when using the direct $3 \mathrm{D}$ radiative transfer model as compared to the weighted average (Figure 8c). The absolute difference varied between -0.10 and 0.06 , on average $3 \%$ of the total $f_{\text {APAR }}$. However, the difference between $\mathrm{f}_{\text {APAR }}$ modelled with DART and $\mathrm{f}_{\mathrm{APAR}}$ calculated from weighted averages was not significant $(p>0.1)$.

\section{Discussion}

\subsection{Vegetation map and canopy characteristics}

Our vegetation map had a Kappa coefficient of 0.44 with the original nine land cover classes. The achieved accuracy was lower than in other studies classifying tundra vegetation using orthomosaics (Lantz et al., 2010; Muster et al., 2012) or high resolution satellite imagery (Atkinson \& Treitz, 2012; Virtanen \& Ek, 2014; Siewert et al., 2015). The lower accuracies of our classification were mostly due to similar reflectance properties of several classes in the four spectral bands which were available.

The vegetation classification accuracy and the 3D modelling (Figure 5a) indicate that several of the pre-defined vegetation classes have similar reflectance properties. This functional similarity is in contrast to the differences among vegetation types in terms of species composition and canopy properties such as height or PAI. As these canopy properties translate into specific radiation transmittance and absorptance characteristics, they play an important part in the radiation budget at the landscape scale and are thus included in the 3D radiative transfer modelling. Given that several structurally different classes had similar reflectance properties, more information is needed to reliably estimate tundra vegetation distribution and structural complexity. One approach is to use more spectral bands for vegetation mapping. Several studies show that hyperspectral data enable estimates of canopy composition (Antonarakis et al., 2014; Bratsch et al., 2016) and structure (Asner, 1998). At the local scale, 
the use of LiDAR to estimate canopy structural properties could be considered (Antonarakis et al., 2014; Schneider et al., 2014).

Model input variables and parameters were subject to uncertainties based on the field measurements and the spatial extrapolation. Despite our correction, the Ocean Optics leaf optical properties measurements were affected by the small size of the two integrating spheres (Section A.3). Furthermore, we used optical properties of a single species for all species in the three near-infrared wavebands (Figure A3). However, pre-experimental tests with the DART model showed that leaf optical properties were generally less important than other factors, in particular the leaf angle distribution, PAI, and leaf to wood ratio. Thus, we expect that other differences between the vegetation types, such as the LAI, are more important controls of the (broadband) radiation budget.

We used field observations of spatial LAI variability within vegetation classes and an NDVI map to extrapolate LAI over the whole study region. Several studies have shown strong relationships between NDVI and LAI in Arctic tundra (Shippert et al., 1995; Riedel et al., 2005; Campioli et al., 2009), especially if each vegetation type was treated separately (Street et al., 2007). Williams et al. (2001) estimated a mean error of prediction of around 16\% when extrapolating tundra LAI based on NDVI. However, we were not able to validate the spatial LAI distribution due to a lack of observations in the same time period as the orthophotos. All other input variables, namely wood area index, standing dead leaf area index, canopy height, and standing dead leaf height, were extrapolated based on linear relationships with LAI. We are not aware of any other study which spatially extrapolated these canopy characteristics in a tundra ecosystem. Given the uncertainties in the field measurements, the NDVI, and the vegetation map, the spatial distribution of LAI and the other canopy variables is uncertain. However, we ensured that the range, mean values, and variability were wellrepresented in the modelling. While the uncertainty of input variables limits our ability to predict the radiation budget at specific locations, it still allows us to investigate the importance of different drivers for the radiation budget at local and landscape scale as well as the role of the spatial vegetation distribution. 
We found that green leaves only contributed about one half to the total PAI. The importance of wood for Arctic shrub canopies has been highlighted by Thompson et al. (2004) who measured larger wood area indices than leaf area indices in tundra shrubs. Juszak et al. (2014) emphasised the role of wood for the radiation absorption of tundra dwarf shrubs. The large area of standing dead sedge leaves found at our study site is relevant for the radiation budget, as dead leaves can contribute significantly to canopy reflectance (Chapin et al., 2000) and shading (Caldwell et al., 1974). We included all vegetation above $5 \mathrm{~cm}$ height (cell size) as turbid media in the radiative transfer model, while lower vegetation and mosses were included as background and thus did not contribute to $f_{A P A R}$ and soil shading. Therefore, we likely underestimate $f_{A P A R}$ at most vegetation types as moss and lichen cover is very common. However, understory light extinction is not commonly included in the $\mathrm{f}_{\mathrm{APAR}}$ definition (Huemmrich et al., 2010). As mosses may account for a significant part of tundra absorbed radiation and gross ecosystem production (Huemmrich et al., 2010), further research is required on how to accurately represent mosses in radiation transfer and land surface models.

\subsection{Small scale spatial variation in albedo, transmittance, and $f_{A P A R}$}

In agreement with Oliphant et al. (2006), we found that at the $5 \mathrm{~cm}$ pixel and the patch scale albedo, transmittance, and $\mathrm{f}_{\mathrm{APAR}}$ can be substantially different from mean values of the respective vegetation types (Figure 5). We found that the scale of the variability in radiation budget components is much smaller than what we can observe from satellites, posing challenges for driving models from conventional remote sensing. The suitability of satellite observations for shortwave radiation budget studies is also limited by the low correlation between albedo and transmittance or $\mathrm{f}_{\mathrm{APAR}}$, in particular at the local scale. This weak relationship between the more easily observable albedo and transmittance is relevant for permafrost research. Shading (i.e. inverse of transmittance) by shrubs has been found to influence permafrost thaw locally (Briggs et al., 2014) through the amount of solar energy at the soil surfaces. Canopy transmittance 
also affects soil surface temperature (Smith, 1975) and thus longwave radiation and sensible heat fluxes (Ni-Meister \& Gao, 2011). Our results concerning transmittance indicate, that the shortwave radiation budget at the soil surface is highly variable, strongly related to plant area, and only weakly related with canopy reflectance.

Several studies have shown that the heterogeneity of the light regime within the canopy affects ecosystem processes. In particular, $\mathrm{f}_{\mathrm{APAR}}$ and its variability affect the canopy energy, water, and carbon budget of tundra ecosystems (Caldwell et al., 1974; Huemmrich et al., 2010; Tagesson et al., 2012; Huemmrich et al., 2013). For example, evapotranspiration is sensitive to spatial heterogeneity of radiation within the canopy (Song et al., 2009; He et al., 2014). He et al. (2014) simulated lower water stress in a forest with a model that included 3D radiative fluxes and canopy structure as compared to a homogeneous case due to the light limited vegetation in shaded areas. Furthermore, the carbon budget is influenced by spatial heterogeneity of radiation. Light Use Efficiency not only depends strongly on vegetation type and related hydrological conditions (Huemmrich et al., 2013), but also on light heterogeneity caused by self-shading (Huemmrich et al., 2010; Williams et al., 2014). Consequently, Sprintsin et al. (2012) showed strong effects of the radiation scheme on modelled gross primary production. Thus, the high local variability of the shortwave radiation budget is relevant for a number of land-climate feedbacks.

Edge effects extended to larger patches for canopy transmittance as compared to albedo and $\mathrm{f}_{\mathrm{APAR}}$. This may be a consequence of the different heights being relevant for each radiation process. While albedo and $\mathrm{f}_{\mathrm{APAR}}$ are determined by the mean scattering centre of the canopy, transmittance is defined below canopy. Thus lateral shading may affect the radiation at soil level further away from the tall elements. The characteristic length scale differed between vegetation types, which indicates complex interaction between the spatial vegetation distribution and the radiation budget.

The edge effects and length scales found in this study likely depend on the irradiance conditions. Our work was conducted for a unique illumination con- 
figuration. While we simulated clear-sky conditions, a higher fraction of diffuse light generally lowers the albedo (Eugster et al., 2000), an effect observed more strongly in wet sedge tundra as compared to dwarf shrub tundra (Juszak et al., 2016). Cloud cover also increases wet sedge transmittance more strongly than dwarf shrub transmittance (Juszak et al., 2016). Therefore changes in irradiance conditions will likely have different effects on the spatial variability of the radiation budget, depending on vegetation type. Furthermore, the time within the growing season influences sun angles and canopy and background properties and thus the radiation budget. Field measurements generally show an increase in tundra (and shrub specifically) albedo in the course of the summer (Lafleur et al., 1997; Lloyd et al., 2001). This seasonal albedo variation is influenced by vegetation development, structure, and background properties, and therefore depends on vegetation type (Juszak et al., 2016). As our study focusses on a single time-point, this temporal evolution is not included. Further research and temporally-resolved input and validation data are needed to quantify the seasonal cycle of all radiation budget components for each vegetation type.

\subsection{Drivers of the radiation budget at the landscape scale}

We found that the fraction of standing water was by far the most important driver of landscape albedo (Table 5). Thus, currently observed changes in water cover (Smith et al., 2005; Carroll et al., 2011; Lin et al., 2012) will likely affect the tundra energy budget strongly. The importance of standing water for spatial and temporal tundra albedo variations has been highlighted in several studies (Lafleur et al., 1997; Gamon et al., 2012) and has been acknowledged by defining lake area as essential climate variable (Bojinski et al., 2014). However, we consider water bodies of very small spatial extent, typically covering only a few square metres. Arctic tundra often comprises such small scale water bodies that cannot be detected based on medium resolution satellite imagery such as Landsat-7 (Muster et al., 2012; Virtanen \& Ek, 2014). In polygonal tundra, this can lead to a $35 \%$ lower estimate of water surface area and translate into high uncertainties in energy fluxes, especially evapotranspiration (Muster et al., 
2012). While small water bodies are included in the satellite albedo estimates, they are neglected in medium and large scale land cover maps (such as Gould et al., 2003; Walker et al., 2005). As our modelling results highlighted that the fraction of standing water was strongly influencing tundra albedo, simplified land cover maps and underestimation of the water surface area can affect large scale modelling results, especially in wetlands. Our results showed that wetlands with high cover of peat mosses or dry sedges had the highest albedo within the tundra landscape at our site, while water bodies and waterlogged sedges had the lowest albedo (Figure 5). Land cover and vegetation type in these lowlands are highly dependent on the hydrological conditions. Even under predicted permafrost thaw, the hydrological implications are highly uncertain (Walvoord \& Kurylyk, 2016).

The second significant driver of landscape albedo was shrub cover, which was more important than PAI. The importance of shrub cover is well known, as shrub expansion is associated with a positive feedback to global warming (Chapin et al., 2005; Blok et al., 2011b; Lawrence \& Swenson, 2011). However, at the larger scales shrub cover and PAI are linked (Thompson et al., 2004; Beringer et al., 2005) and their relative importance for growing season albedo cannot easily be disentangled in modelling studies that increase both values simultaneously (such as in Lawrence \& Swenson, 2011; Bonfils et al., 2012).

PAI explained almost all variability in transmittance and $\mathrm{f}_{\mathrm{APAR}}$ among the strip transects. The importance of PAI for $\mathrm{f}_{\mathrm{APAR}}$ (Myneni et al., 1997; Asner et al., 1998; Shabanov et al., 2000) and transmittance has been highlighted in other studies (Flerchinger et al., 2009; Juszak et al., 2014). At the landscape scale, edge effects did not significantly influence the radiative budget (Table 5).

Albedo was only weakly related to transmittance and $\mathrm{f}_{\mathrm{APAR}}$ at the landscape scale and even less at the local scale. An accurate estimate of PAI is important for transmittance estimates and thus for assessing the energy budget at the soil surface. 


\subsection{Influence of spatial distribution and interaction of land cover types}

At the landscape scale, our direct 3D model results were very similar to the results of the weighted averages and the difference of $3 \%$ is likely within the model uncertainty (Figure 8). However, the higher albedo estimate using simple weighted averages in a complex landscape is consistent with studies of the forest and the global radiation budget (Rowe, 1993; Yuan et al., 2014). The small effect may be due to low canopy height in our simulations (Dickinson et al., 2008). The bias in albedo resulting from the direct 3D versus weighted average modelling approaches needs further investigation, such as a comparison to field measurements with fully characterized uncertainties. This detailed validation will help to identify the appropriate model complexity and grain size depending on the scale of interest.

Simulations with the direct 3D approach on average increased canopy transmittance by only $3 \%$ as compared to the simple approach. The lower transmittance estimate by simple models is consistent with Knyazikhin et al. (1997), who found that $1 \mathrm{D}$ simulations overestimate the decline of solar radiation in a canopy with depth.

In line with albedo and transmittance, the $\mathrm{f}_{\mathrm{APAR}}$ results revealed little differences between the direct 3D model and a weighted average, while other studies report significant underestimation of $\mathrm{f}_{\mathrm{APAR}}$ using 1D models (Kobayashi et al., 2014; Loew et al., 2014; Yuan et al., 2014). Kobayashi et al. (2014) show that 1D simulations in boreal forests underestimate the fraction of light absorbed by the canopy $\left(\mathrm{f}_{\mathrm{APAR}}\right)$ by about $50 \%$. As for albedo and transmittance, the small differences between the direct 3D model and weighted averages that we found is most likely due to the short-statured vegetation at our study site. The tundra canopy in our model is less than $80 \mathrm{~cm}$ tall. Additionally, we explicitly include canopy gaps as independent vegetation types in both simulations, direct 3D and weighted averages.

Overall, we find that tundra albedo, transmittance, and $\mathrm{f}_{\mathrm{APAR}}$ are less sensitive to the spatial distribution and interaction of land cover types (as indicated by different model complexities) than to land cover type and canopy charac- 
teristics at the landscape scale. As the effect of different model complexities is much smaller than the variability among the strip transects, we suggest that more effort should be made to estimate water cover, shrub cover, and PAI than toward more physically based modelling at the landscape scale. However, the 3D model results depend on the model parametrisation and may differ more strongly from weighted averages when plants are simulated as objects instead of turbid media, or when the turbid media include vertical gradients. Furthermore, the influence of model complexity on the results strongly depends on the scale of interest. While direct 3D radiative transfer modelling may not be needed for radiative fluxes at the landscape scale, we find that at the small scale the heterogeneity of the radiation budget can be substantial. Thus, 3D modelling may be required in case of non-linear feedbacks.

\section{Conclusions}

Our modelling results show that the surface area of water bodies and waterlogged sedges is the most important driver of tundra albedo in summer, even at small scales where current Earth observation satellites will not be able to assess the process of dynamic changes in water body size due to their spatial resolution. Shrub cover is the second most important control and explains more of the spatial albedo variations than PAI. Canopy transmittance and absorbed PAR are almost entirely controlled by PAI at the landscape scale. At the landscape scale, the effect of model complexities with and without spatial heterogeneity is much smaller than the variability depending on the cover type and canopy plant area. Therefore, accurate validation data would be needed to determine the most suitable model complexity. However, using the direct $3 \mathrm{D}$ radiative transfer model we found considerable variability of albedo, transmittance, and canopy absorbed PAR at the scale of a few centimetres, which cannot be easily observed from satellite. As local radiation variability influences photosynthesis and evapotranspiration, it should be considered in modelling studies of the tundra energy or water budget. If coarse satellite data are the major model input, 
the local radiation variability and associated feedbacks should be parametrised using sub-grid scale models. We recommend assessing this local scale radiation variability at large scales as well, to determine if water cover and PAI influence albedo in a similar fashion. Building on our results on the shortwave radiation budget, an analysis of non-linear feedback mechanisms between radiation, evapotranspiration, and photosynthesis is needed to draw conclusions on changes of the Arctic energy budget. Our results highlight the importance of small water bodies, shrub cover, and the PAI, which does not only include green leaves but also standing dead leaves and wood. As very little data on standing dead leaves and wood are currently available, we propose more field measurements of these components to allow for more detailed parametrisations in land surface models. Furthermore, we propose to extend the analysis from spatial to spatio-temporal radiation variability. In this way, vegetation, irradiance, and snow dynamics could be included.

\section{Acknowledgements}

We thank Tim Grünberg, Institute of Fluid Dynamics, ETH Zurich, for helping with the projection of leaf angles, raster calculations, and computational resources. This work is supported by the Swiss National Science Foundation through project grant 140631 and by the University of Zurich research priority program on Global Change and Biodiversity (URPP GCB).

\section{References}

Antonarakis, A. S., Munger, J. W., \& Moorcroft, P. R. (2014). Imaging spectroscopyand lidar-derived estimates of canopy composition and structure to improve predictions of forest carbon fluxes and ecosystem dynamics. Geophysical Research Letters, 41, 2535-2542. doi:10.1002/2013GL058373. 2013GL058373.

Asner, G. P. (1998). Biophysical and biochemical sources of variability in canopy reflectance. Remote Sensing of Environment, 64, 234-253. doi:10.1016/ S0034-4257(98)00014-5. 
Asner, G. P., Wessman, C. A., \& Archer, S. (1998). Scale dependence of absorption of photosynthetically active radiation in terrestrial ecosystems. Ecological Applications, 8, 1003-1021. doi:10.1890/1051-0761(1998)008[1003:SDOAOP] 2.0.C0;2.

Atkinson, D. M., \& Treitz, P. (2012). Arctic ecological classifications derived from vegetation community and satellite spectral data. Remote Sensing, 4, 3948-3971. doi:10.3390/rs4123948.

Benninghoff, W. S. (1952). Interaction of vegetation and soil frost phenomena. Arctic, $5,34-44$

Beringer, J., Chapin, F. S., III, Thompson, C. C., \& McGuire, A. D. (2005). Surface energy exchanges along a tundra-forest transition and feedbacks to climate. Agricultural and Forest Meteorology, 131, 143-161. doi:10.1016/j . agrformet .2005.05. 006.

Beringer, J., Lynch, A. H., Chapin, F. S., III, Mack, M., \& Bonan, G. B. (2001). The representation of Arctic soils in the land surface model: The importance of mosses. Journal of Climate, 14, 3324-3335. doi:10.1175/1520-0442(2001) $014<3324:$ TROASI $>2.0 . \mathrm{CO} ; 2$.

Blok, D., Heijmans, M. M. P. D., Schaepman-Strub, G., van Ruijven, J., Parmentier, F. J. W., Maximov, T. C., \& Berendse, F. (2011a). The cooling capacity of mosses: Controls on water and energy fluxes in a Siberian tundra site. Ecosystems, 14, 1055-1065. doi:10.1007/s10021-011-9463-5.

Blok, D., Schaepman-Strub, G., Bartholomeus, H., Heijmans, M. M. P. D., Maximov, T. C., \& Berendse, F. (2011b). The response of Arctic vegetation to the summer climate: relation between shrub cover, NDVI, surface albedo and temperature. Environmental Research Letters, 6, 035502. doi:10.1088/1748-9326/6/3/035502.

Bojinski, S., Verstraete, M., Peterson, T. C., Richter, C., Simmons, A., \& Zemp, M. (2014). The concept of essential climate variables in support of climate research. Bulletin of the American Meteorological Society, 95, 1431-1443. doi:10. 1175/BAMS-D-13-00047.1.

Bonfils, C. J. W., Phillips, T. J., Lawrence, D. M., Cameron-Smith, P., Riley, W. J., \& Subin, M. (2012). On the influence of shrub height and expansion on northern high 
latitude climate. Environmental Research Letters, 7, 15503-15511. doi:10.1088/ $1748-9326 / 7 / 1 / 015503$.

Boudreau, L. D., \& Rouse, W. R. (1995). The role of individual terrain units in the water balance of wetland tundra. Climate Research, 5, 31-47. doi:10.3354/ cr005031.

Bratsch, S. N., Epstein, H. E., Buchhorn, M., \& Walker, D. A. (2016). Differentiating among four Arctic tundra plant communities at Ivotuk, Alaska using field spectroscopy. Remote Sensing, 8, 51. doi:10.3390/rs8010051.

Bret-Harte, M. S., Shaver, G. R., Zoerner, J. P., Johnstone, J. F., Wagner, J. L., Chavez, A. S., Gunkelman, R. F., IV, Lippert, S. C., \& Laundre, J. A. (2001). Developmental plasticity allows Betula nana to dominate tundra subjected to an altered environment. Ecology, 82, 18-32. doi:10.1890/0012-9658(2001) 082 [0018: DPABNT] 2.0.CO;2.

Briggs, M. A., Walvoord, M. A., McKenzie, J. M., Voss, C. I., Day-Lewis, F. D., \& Lane, J. W. (2014). New permafrost is forming around shrinking Arctic lakes, but will it last? Geophysical Research Letters, 41, 1585-1592. doi:10.1002/ 2014 GL059251.

Caldwell, M. M., Tieszen, L. L., \& Fareed, M. (1974). The canopy structure of tundra plant communities at Barrow, Alaska, and Niwot Ridge, Colorado. Arctic and Alpine Research, 6, 151-159. doi:10.2307/1550083.

Campioli, M., Street, L. E., Michelsen, A., Shaver, G. R., Maere, T., Samson, R., \& Lemeur, R. (2009). Determination of leaf area index, total foliar N, and normalized difference vegetation index for arctic ecosystems dominated by Cassiope tetragona. Arctic, Antarctic, and Alpine Research, 41, 426-433. doi:10.1657/1938-4246-41. 4.426 .

Cannone, N., \& Guglielmin, M. (2009). Influence of vegetation on the ground thermal regime in continental Antarctica. Geoderma, 151, 215-223. doi:10.1016/j. geoderma.2009.04.007.

Carroll, M. L., Townshend, J. R. G., DiMiceli, C. M., Loboda, T., \& Sohlberg, R. A. 
(2011). Shrinking lakes of the Arctic: Spatial relationships and trajectory of change. Geophysical Research Letters, 38, L20406. doi:10.1029/2011GL049427.

Chapin, F. S., III, Eugster, W., McFadden, J. P., Lynch, A. H., \& Walker, D. A. (2000). Summer differences among Arctic ecosystems in regional climate forcing. Journal of Climate, 13 , 2002-2010. doi:10 .1175/1520-0442(2000)013<2002 : SDAAEI>2 . 0 . C0; 2 .

Chapin, F. S., III, Sturm, M., Serreze, M. C., McFadden, J. P., Key, J. R., Lloyd, A. H., McGuire, A. D., Rupp, T. S., Lynch, A. H., Schimel, J. P., Beringer, J., Chapman, W. L., Epstein, H. E., Euskirchen, E. S., Hinzman, L. D., Jia, G., Ping, C.-L., Tape, K. D., Thompson, C. D. C., Walker, D. A., \& Welker, J. M. (2005). Role of land-surface changes in Arctic summer warming. Science, 310, 657-660. doi:10.1126/science. 1117368 .

Chaplot, V., Darboux, F., Bourennane, H., Leguédois, S., Silvera, N., \& Phachomphon, K. (2006). Accuracy of interpolation techniques for the derivation of digital elevation models in relation to landform types and data density. Geomorphology, 77, 126-141. doi:10.1016/j.geomorph.2005.12.010.

Congalton, R. G. (1991). A review of assessing the accuracy of classifications of remotely sensed data. Remote Sensing of Environment, 37, 35-46. doi:10.1016/ 0034-4257 (91) 90048-B.

Dickinson, R. E., Zhou, L., Tian, Y., Liu, Q., Lavergne, T., Pinty, B., Schaaf, C. B., \& Knyazikhin, Y. (2008). A three-dimensional analytic model for the scattering of a spherical bush. Journal of Geophysical Research: Atmospheres, 113, D20113. doi:10.1029/2007JD009564.

Duthoit, S., Demarez, V., Gastellu-Etchegorry, J.-P., Martin, E., \& Roujean, J.-L. (2008). Assessing the effects of the clumping phenomenon on BRDF of a maize crop based on 3D numerical scenes using DART model. Agricultural and Forest Meteorology, 148, 1341-1352. doi:10.1016/j.agrformet.2008.03.011.

Eugster, W., Rouse, W. R., Pielke Sr, R. A., Mcfadden, J. P., Baldocchi, D. D., Kittel, T. G. F., Chapin, F. S., III, Liston, G. E., Vidale, P. L., Vaganov, E., \& Chambers, S. (2000). Land-atmosphere energy exchange in Arctic tundra and 
boreal forest: available data and feedbacks to climate. Global Change Biology, 6, 84-115. doi:10.1046/j.1365-2486.2000.06015.x.

Flerchinger, G. N., Xiao, W., Sauer, T. J., \& Yu, Q. (2009). Simulation of withincanopy radiation exchange. Wageningen Journal of Life Sciences, 57, 5-15. doi:10. $1016 /$ j.njas.2009.07.004.

Fraser, R. H., Lantz, T. C., Olthof, I., Kokelj, S. V., \& Sims, R. A. (2014). Warminginduced shrub expansion and lichen decline in the Western Canadian Arctic. Ecosystems, 17, 1151-1168. doi:10.1007/s10021-014-9783-3.

Gamon, J. A., Kershaw, G. P., Williamson, S., \& Hik, D. S. (2012). Microtopographic patterns in an arctic baydjarakh field: do fine-grain patterns enforce landscape stability? Environmental Research Letters, 7, 015502. doi:10.1088/1748-9326/7/ $1 / 015502$.

Gastellu-Etchegorry, J.-P., Demarez, V., Pinel, V., \& Zagolski, F. (1996). Modeling radiative transfer in heterogeneous $3-\mathrm{D}$ vegetation canopies. Remote Sensing of Environment, 58, 131-156. doi:10.1016/0034-4257(95)00253-7.

Gastellu-Etchegorry, J.-P., Yin, T., Lauret, N., Cajgfinger, T., Gregoire, T., Grau, E., Feret, J.-B., Lopes, M., Guilleux, J., Dedieu, G., Malenovský, Z., Cook, B. D., Morton, D., Rubio, J., Durrieu, S., Cazanave, G., Martin, E., \& Ristorcelli, T. (2015). Discrete Anisotropic Radiative Transfer (DART 5) for modeling airborne and satellite spectroradiometer and LIDAR acquisitions of natural and urban landscapes. Remote Sensing, 7, 1667-1701. doi:10.3390/rs70201667.

Goel, N. S., \& Strebel, D. E. (1984). Simple beta distribution representation of leaf orientation in vegetation canopies. Agronomy Journal, 76, 800-802. doi:10.2134/ agronj1984.00021962007600050021x.

Gould, W. A., Raynolds, M., \& Walker, D. A. (2003). Vegetation, plant biomass, and net primary productivity patterns in the Canadian Arctic. Journal of Geophysical Research: Atmospheres, 108, 8167. doi:10.1029/2001JD000948.

Grau, E., \& Gastellu-Etchegorry, J.-P. (2013). Radiative transfer modeling in the Earth-Atmosphere system with DART model. Remote Sensing of Environment, 139, 149-170. doi:10.1016/j.rse.2013.07.019. 
He, L., Ivanov, V. Y., Bohrer, G., Maurer, K. D., Vogel, C. S., \& Moghaddam, M. (2014). Effects of fine-scale soil moisture and canopy heterogeneity on energy and water fluxes in a northern temperate mixed forest. Agricultural and Forest Meteorology, 184, 243-256. doi:10.1016/j.agrformet.2013.10.006.

Huemmrich, K. F., Gamon, J. A., Tweedie, C. E., Campbell, P. K. E., Landis, D. R., \& Middleton, M. (2013). Arctic tundra vegetation functional types based on photosynthetic physiology and optical properties. Selected Topics in Applied Earth Observations and Remote Sensing, IEEE Journal of, 6, 265-275. doi:10.1109/JSTARS. 2013.2253446.

Huemmrich, K. F., Gamon, J. A., Tweedie, C. E., Oberbauer, S. F., Kinoshita, G., Houston, S., Kuchy, A., Hollister, R. D., Kwon, H., Mano, M., Harazono, Y., Webber, P. J., \& Oechel, W. C. (2010). Remote sensing of tundra gross ecosystem productivity and light use efficiency under varying temperature and moisture conditions. Remote Sensing of Environment, 114, 481-489. doi:10.1016/j.rse.2009. 10.003.

Jacquez, J. A., \& Kuppenheim, H. F. (1955). Theory of the integrating sphere. Journal of the Optical Society of America, 45, 460-466. doi:10.1364/JOSA.45.000460.

Jones, B. M., Grosse, G., Arp, C. D., Jones, M. C., Walter Anthony, K. M., \& Romanovsky, V. E. (2011). Modern thermokarst lake dynamics in the continuous permafrost zone, northern Seward Peninsula, Alaska. Journal of Geophysical Research: Biogeosciences, 116, G00M03. doi:10.1029/2011JG001666.

Juszak, I., Erb, A. M., Maximov, T. C., \& Schaepman-Strub, G. (2014). Arctic shrub effects on NDVI, summer albedo and soil shading. Remote Sensing of Environment, 153, 79-89. doi:10.1016/j.rse.2014.07.021.

Juszak, I., Eugster, W., Heijmans, M. M. P. D., \& Schaepman-Strub, G. (2016). Contrasting radiation and soil heat fluxes in Arctic shrub and wet sedge tundra. Biogeosciences, 13, 4049-4064. doi:10.5194/bg-13-4049-2016.

Knyazikhin, Y., Mießen, G., Panfyorov, O., \& Gravenhorst, G. (1997). Smallscale study of three-dimensional distribution of photosynthetically active radiation in a forest. Agricultural and Forest Meteorology, 88, 215-239. doi:10.1016/ S0168-1923(97)00036-1. 
Kobayashi, H., Suzuki, R., Nagai, S., Nakai, T., \& Kim, Y. (2014). Spatial scale and landscape heterogeneity effects on FAPAR in an open-canopy black spruce forest in interior Alaska. Geoscience and Remote Sensing Letters, IEEE, 11, 564-568. doi:10.1109/LGRS. 2013.2278426.

Lafleur, P. M., Wurtele, A. B., \& Duguay, C. R. (1997). Spatial and temporal variations in surface albedo of a subarctic landscape using surface-based measurements and remote sensing. Arctic and Alpine Research, 29, 261-269. doi:10.2307/1552140.

Lantz, T. C., Gergel, S. E., \& Kokelj, S. V. (2010). Spatial heterogeneity in the shrub tundra ecotone in the Mackenzie delta region, Northwest Territories: Implications for Arctic environmental change. Ecosystems, 13, 194-204. doi:10.1007/ s10021-009-9310-0.

Lawrence, D. M., \& Swenson, S. C. (2011). Permafrost response to increasing Arctic shrub abundance depends on the relative influence of shrubs on local soil cooling versus large-scale climate warming. Environmental Research Letters, 6, 045504. doi:10.1088/1748-9326/6/4/045504.

Liang, S., Strahler, A. H., \& Walthall, C. (1999). Retrieval of land surface albedo from satellite observations: A simulation study. Journal of Applied Meteorology, 38, 712-725. doi:10.1175/1520-0450(1999) 038<0712:ROLSAF>2 . 0.CO;2.

Lin, D. H., Johnson, D. R., Andresen, C., \& Tweedie, C. E. (2012). High spatial resolution decade-time scale land cover change at multiple locations in the Beringian Arctic (1948-2000s). Environmental Research Letters, 7, 025502. doi:10.1088/ $1748-9326 / 7 / 2 / 025502$.

Lloyd, C. R., Harding, R. J., Friborg, T., \& Aurela, M. (2001). Surface fluxes of heat and water vapour from sites in the European Arctic. Theoretical and Applied Climatology, 70, 19-33. doi:10.1007/s007040170003.

Loew, A., van Bodegom, P. M., Widlowski, J.-L., Otto, J., Quaife, T., Pinty, B., \& Raddatz, T. (2014). Do we (need to) care about canopy radiation schemes in DGVMs? Caveats and potential impacts. Biogeosciences, 11, 1873-1897. doi:10. $5194 /$ bg-11-1873-2014. 
Loranty, M. M., Goetz, S. J., \& Beck, P. S. A. (2011). Tundra vegetation effects on pan-Arctic albedo. Environmental Research Letters, 6, 024014. doi:10.1088/ $1748-9326 / 6 / 2 / 024014$.

Malenovský, Z., Martin, E., Homolová, L., Gastellu-Etchegorry, J.-P., Zurita-Milla, R., Schaepman, M. E., Pokorný, R., Clevers, J. G. P. W., \& Cudlín, P. (2008). Influence of woody elements of a Norway spruce canopy on nadir reflectance simulated by the DART model at very high spatial resolution. Remote Sensing of Environment, 112, 1-18. doi:10.1016/j.rse.2006.02.028.

McFadden, J. P., Eugster, W., \& Chapin, F. S., III (2003). A regional study of the controls on water vapor and $\mathrm{CO}_{2}$ exchange in Arctic tundra. Ecology, 84, 27622776. doi:10.1890/01-0444.

Mi, Y., van Huissteden, J., Parmentier, F. J. W., Gallagher, A., Budishchev, A., Berridge, C. T., \& Dolman, A. J. (2014). Improving a plot-scale methane emission model and its performance at a northeastern Siberian tundra site. Biogeosciences, 11, 3985-3999. doi:10.5194/bg-11-3985-2014.

van der Molen, M. K., van Huissteden, J., Parmentier, F. J. W., Petrescu, A. M. R., Dolman, A. J., Maximov, T. C., Kononov, A. V., Karsanaev, S. V., \& Suzdalov, D. A. (2007). The growing season greenhouse gas balance of a continental tundra site in the Indigirka lowlands, NE Siberia. Biogeosciences, 4, 985-1003. doi:10. $5194 /$ bg-4-985-2007.

Muster, S., Langer, M., Heim, B., Westermann, S., \& Boike, J. (2012). Subpixel heterogeneity of ice-wedge polygonal tundra: a multi-scale analysis of land cover and evapotranspiration in the Lena River Delta, Siberia. Tellus B, 64, 17301. doi:10.3402/tellusb.v64i0.17301.

Myers-Smith, I. H., Forbes, B. C., Wilmking, M., Hallinger, M., Lantz, T., Blok, D., Tape, K. D., Macias-Fauria, M., Sass-Klaassen, U., Lévesque, E., Boudreau, S., Ropars, P., Hermanutz, L., Trant, A., Collier, L. S., Weijers, S., Rozema, J., Rayback, S. A., Schmidt, N. M., Schaepman-Strub, G., Wipf, S., Rixen, C., Ménard, C. B., Venn, S., Goetz, S., Andreu-Hayles, L., Elmendorf, S., Ravolainen, V., Welker, J., Grogan, P., Epstein, H. E., \& Hik, D. S. (2011). Shrub expansion 
in tundra ecosystems: dynamics, impacts and research priorities. Environmental Research Letters, 6, 045509. doi:10.1088/1748-9326/6/4/045509.

Myneni, R. B., Ramakrishna, R., Nemani, R., \& Running, S. W. (1997). Estimation of global leaf area index and absorbed PAR using radiative transfer models. Geoscience and Remote Sensing, IEEE Transactions on, 35, 1380-1393. doi:10.1109/36.649788.

Nauta, A. L., Heijmans, M. M. P. D., Blok, D., Limpens, J., Elberling, B., Gallagher, A., Li, B., Petrov, R. E., Maximov, T. C., van Huissteden, J., \& Berendse, F. (2015). Permafrost collapse after shrub removal shifts tundra ecosystem to a methane source. Nature Climate Change, 5, 67-70. doi:10.1038/nclimate2446.

Ni-Meister, W., \& Gao, H. (2011). Assessing the impacts of vegetation heterogeneity on energy fluxes and snowmelt in boreal forests. Journal of Plant Ecology, 4, 37-47. doi:10.1093/jpe/rtr004.

Oechel, W. C., Vourlitis, G. L., Hastings, S. J., Zulueta, R. C., Hinzman, L., \& Kane, D. (2000). Acclimation of ecosystem $\mathrm{CO}_{2}$ exchange in the Alaskan Arctic in response to decadal climate warming. Nature, 406, 978-981. doi:10.1038/35023137.

Oliphant, A., Susan, C., Grimmond, B., Schmid, H.-P., \& Wayson, C. A. (2006). Localscale heterogeneity of photosynthetically active radiation (PAR), absorbed PAR and net radiation as a function of topography, sky conditions and leaf area index. Remote Sensing of Environment, 103, 324-337. doi:10.1016/j.rse.2005.09.021.

Pinty, B., Gobron, N., Widlowski, J.-L., Gerstl, S. A. W., Verstraete, M. M., Antunes, M., Bacour, C., Gascon, F., Gastellu, J.-P., Goel, N., Jacquemoud, S., North, P., Qin, W., \& Thompson, R. (2001). Radiation transfer model intercomparison (RAMI) exercise. Journal of Geophysical Research: Atmospheres, 106, 1193711956. doi:10.1029/2000JD900493.

Pisek, J., Ryu, Y., \& Alikas, K. (2011). Estimating leaf inclination and G-function from leveled digital camera photography in broadleaf canopies. Trees, 25, 919-924. doi:10.1007/s00468-011-0566-6.

Pomeroy, J. W., Bewley, D. S., Essery, R. L. H., Hedstrom, N. R., Link, T., Granger, 
R. J., Sicart, J. E., Ellis, C. R., \& Janowicz, J. R. (2006). Shrub tundra snowmelt. Hydrological Processes, 20, 923-941. doi:10.1002/hyp.6124.

R Core Team (2015). R: A Language and Environment for Statistical Computing. $\mathrm{R}$ Foundation for Statistical Computing Vienna, Austria. URL: https: //www.R-project.org/.

Riedel, S. M., Epstein, H. E., \& Walker, D. A. (2005). Biotic controls over spectral reflectance of Arctic tundra vegetation. International Journal of Remote Sensing, 26, 2391-2405. doi:10.1080/01431160512331337754.

Romanovskii, N. N., Hubberten, H.-W., Gavrilov, A. V., Tumskoy, V. E., \& Kholodov, A. L. (2004). Permafrost of the east Siberian Arctic shelf and coastal lowlands. Quaternary Science Reviews, 23, 1359-1369. doi:10.1016/j.quascirev.2003.12. 014.

Rowe, C. M. (1993). Incorporating landscape heterogeneity in land surface albedo models. Journal of Geophysical Research: Atmospheres, 98, 5037-5043. doi:10. 1029/92JD02886.

Ruimy, A., Saugier, B., \& Dedieu, G. (1994). Methodology for the estimation of terrestrial net primary production from remotely sensed data. Journal of Geophysical Research: Atmospheres, 99, 5263-5283. doi:10.1029/93JD03221.

Schneider, F. D., Leiterer, R., Morsdorf, F., Gastellu-Etchegorry, J.-P., Lauret, N., Pfeifer, N., \& Schaepman, M. E. (2014). Simulating imaging spectrometer data: 3D forest modeling based on LiDAR and in situ data. Remote Sensing of Environment, 152, 235-250. doi:10.1016/j.rse.2014.06.015.

Schneider, J., Grosse, G., \& Wagner, D. (2009). Land cover classification of tundra environments in the Arctic Lena Delta based on Landsat 7 ETM + data and its application for upscaling of methane emissions. Remote Sensing of Environment, 113, 380-391. doi:10.1016/j.rse.2008.10.013.

Schuur, E. A. G., Crummer, K. G., Vogel, J. G., \& Mack, M. C. (2007). Plant species composition and productivity following permafrost thaw and thermokarst in Alaskan tundra. Ecosystems, 10, 280-292. doi:10.1007/s10021-007-9024-0. 
Shabanov, N. V., Knyazikhin, Y., Baret, F., \& Myneni, R. B. (2000). Stochastic modeling of radiation regime in discontinuous vegetation canopies. Remote Sensing of Environment, 74, 125-144. doi:10.1016/S0034-4257(00)00128-0.

Shaver, G. R., \& Chapin, F. S., III (1991). Production: Biomass relationships and element cycling in contrasting arctic vegetation types. Ecological Monographs, 61, 1-31. doi:10.2307/1942997.

Shippert, M. M., Walker, D. A., Auerbach, N. A., \& Lewis, B. E. (1995). Biomass and leaf-area index maps derived from SPOT images for Toolik Lake and Imnavait Creek areas, Alaska. Polar Record, 31, 147-154. doi:10.1017/S0032247400013644.

Siewert, M. B., Hanisch, J., Weiss, N., Kuhry, P., Maximov, T. C., \& Hugelius, G. (2015). Comparing carbon storage of Siberian tundra and taiga permafrost ecosystems at very high spatial resolution. Journal of Geophysical Research: Biogeosciences, 120, 1973-1994. doi:10.1002/2015JG002999.

Smith, L. C., Sheng, Y., MacDonald, G. M., \& Hinzman, L. D. (2005). Disappearing Arctic lakes. Science, 308, 1429. doi:10.1126/science.1108142.

Smith, M. W. (1975). Microclimatic influences on ground temperatures and permafrost distribution, Mackenzie Delta, Northwest Territories. Canadian Journal of Earth Sciences, 12, 1421-1438. doi:10.1139/e75-129.

Song, C., Katul, G., Oren, R., Band, L. E., Tague, C. L., Stoy, P. C., \& McCarthy, H. R. (2009). Energy, water, and carbon fluxes in a loblolly pine stand: Results from uniform and gappy canopy models with comparisons to eddy flux data. Journal of Geophysical Research: Biogeosciences, 114. doi:10.1029/2009JG000951. G04021.

Sprintsin, M., Chen, J. M., Desai, A., \& Gough, C. M. (2012). Evaluation of leaf-tocanopy upscaling methodologies against carbon flux data in North America. Journal of Geophysical Research: Biogeosciences, 117. doi:10.1029/2010JG001407. G01023.

Strebel, D. E., Goel, N. S., \& Ranson, K. J. (1985). Two-dimensional leaf orientation distributions. Geoscience and Remote Sensing, IEEE Transactions on, GE-23, 640647. doi:10.1109/TGRS. 1985.289382.

Street, L. E., Shaver, G. R., Williams, M., \& van Wijk, M. T. (2007). What is the relationship between changes in canopy leaf area and changes in photosynthetic 
$\mathrm{CO}_{2}$ flux in arctic ecosystems? Journal of Ecology, 95, 139-150. doi:10.1111/j. $1365-2745.2006 .01187 . \mathrm{x}$

Sturm, M., Racine, C., \& Tape, K. (2001). Increasing shrub abundance in the Arctic. Nature, 411, 546-547. doi:10.1038/35079180.

Tagesson, T., Mastepanov, M., Tamstorf, M. P., Eklundh, L., Schubert, P., Ekberg, A., Sigsgaard, C., Christensen, T. R., \& Ström, L. (2012). High-resolution satellite data reveal an increase in peak growing season gross primary production in a highArctic wet tundra ecosystem 1992-2008. International Journal of Applied Earth Observation and Geoinformation, 18,407-416. doi:10.1016/j.jag.2012.03.016.

Thompson, C., Beringer, J., Chapin, F. S., III, \& McGuire, A. D. (2004). Structural complexity and land-surface energy exchange along a gradient from arctic tundra to boreal forest. Journal of Vegetation Science, 15, 397-406. doi:10.1111/ j.1654-1103.2004.tb02277.x.

Virtanen, T., \& Ek, M. (2014). The fragmented nature of tundra landscape. International Journal of Applied Earth Observation and Geoinformation, 27, 4-12. doi:10.1016/j.jag.2013.05.010.

Walker, D. A., Epstein, H. E., Romanovsky, V. E., Ping, C. L., Michaelson, G. J., Daanen, R. P., Shur, Y., Peterson, R. A., Krantz, W. B., Raynolds, M. K., Gould, W. A., Gonzalez, G., Nicolsky, D. J., Vonlanthen, C. M., Kade, A. N., Kuss, P., Kelley, A. M., Munger, C. A., Tarnocai, C. T., Matveyeva, N. V., \& Daniëls, F. J. A. (2008). Arctic patterned-ground ecosystems: A synthesis of field studies and models along a North American Arctic transect. Journal of Geophysical Research: Biogeosciences, 113, G03S01. doi:10.1029/2007JG000504.

Walker, D. A., Jia, G. J., Epstein, H. E., Raynolds, M. K., Chapin, F. S., III, Copass, C., Hinzman, L. D., Knudson, J. A., Maier, H. A., Michaelson, G. J., Nelson, F., Ping, C. L., Romanovsky, V. E., \& Shiklomanov, N. (2003). Vegetation - soilthaw-depth relationships along a low-arctic bioclimate gradient, Alaska: synthesis of information from the ATLAS studies. Permafrost and Periglacial Processes, 14, 103-123. doi:10.1002/ppp.452.

Walker, D. A., Kuss, P., Epstein, H. E., Kade, A. N., Vonlanthen, C. M., Raynolds, M. K., \& Daniëls, F. J. A. (2011). Vegetation of zonal patterned-ground ecosystems 
along the North America Arctic bioclimate gradient. Applied Vegetation Science, 14, 440-463. doi:10.1111/j.1654-109X.2011.01149.x.

Walker, D. A., Raynolds, M. K., Daniëls, F. J. A., Einarsson, E., Elvebakk, A., Gould, W. A., Katenin, A. E., Kholod, S. S., Markon, C. J., Melnikov, E. S., Moskalenko, N. G., Talbot, S. S., Yurtsev, B. A., \& The other members of the CAVM Team (2005). The Circumpolar Arctic vegetation map. Journal of Vegetation Science, 16, 267-282. doi:10.1111/j.1654-1103.2005.tb02365.x.

Walvoord, M. A., \& Kurylyk, B. L. (2016). Hydrologic impacts of thawing permafrost - A review. Vadose Zone Journal, 15. doi:10.2136/vzj2016.01.0010.

Wang, W.-M., Li, Z.-L., \& Su, H.-B. (2007). Comparison of leaf angle distribution functions: Effects on extinction coefficient and fraction of sunlit foliage. Agricultural and Forest Meteorology, 143, 106-122. doi:10.1016/j.agrformet.2006.12.003.

Widlowski, J.-L., Mio, C., Disney, M., Adams, J., Andredakis, I., Atzberger, C., Brennan, J., Busetto, L., Chelle, M., Ceccherini, G., Colombo, R., Côté, J.-F., Eenmäe, A., Essery, R., Gastellu-Etchegorry, J.-P., Gobron, N., Grau, E., Haverd, V., Homolová, L., Huang, H., Hunt, L., Kobayashi, H., Koetz, B., Kuusk, A., Kuusk, J., Lang, M., Lewis, P. E., Lovell, J. L., Malenovský, Z., Meroni, M., Morsdorf, F., Mõttus, M., Ni-Meister, W., Pinty, B., Rautiainen, M., Schlerf, M., Somers, B., Stuckens, J., Verstraete, M. M., Yang, W., Zhao, F., \& Zenone, T. (2015). The fourth phase of the radiative transfer model intercomparison (RAMI) exercise: Actual canopy scenarios and conformity testing. Remote Sensing of Environment, 169, 418-437. doi:10.1016/j.rse.2015.08.016.

van Wijk, M. T., Clemmensen, K. E., Shaver, G. R., Williams, M., Callaghan, T. V., Chapin, F. S., III, Cornelissen, J. H. C., Gough, L., Hobbie, S. E., Jonasson, S., Lee, J. A., Michelsen, A., Press, M. C., Richardson, S. J., \& Rueth, H. (2003). Longterm ecosystem level experiments at Toolik Lake, Alaska, and at Abisko, Northern Sweden: generalizations and differences in ecosystem and plant type responses to global change. Global Change Biology, 10, 105-123. doi:10.1111/j.1365-2486. 2003.00719.x.

Williams, M., Rastetter, E. B., Van der Pol, L., \& Shaver, G. R. (2014). Arctic canopy photosynthetic efficiency enhanced under diffuse light, linked to a reduction 
in the fraction of the canopy in deep shade. New Phytologist, 202, 1267-1276. doi:10.1111/nph.12750.

Williams, M., Rastetter, E. B., Shaver, G. R., Hobbie, J. E., Carpino, E., \& Kwiatkowski, B. L. (2001). Primary production of an arctic watershed: An uncertainty analysis. Ecological Applications, 11, 1800-1816. doi:10.1890/ 1051-0761(2001)011[1800:PPOAAW] 2.0.CO;2.

Williams, M., Street, L. E., van Wijk, M. T., \& Shaver, G. R. (2006). Identifying differences in carbon exchange among arctic ecosystem types. Ecosystems, 9, 288304. doi:10.1007/s10021-005-0146-y.

de Wit, C. T. (1965). Photosynthesis of leaf canopies. In Agricultural Research Reports no. 663. Centre for Agricultural Publications and Documentation Wageningen. URL: http://edepot.wur.nl/187115.

Yuan, H., Dickinson, R. E., Dai, Y., Shaikh, M. J., Zhou, L., Shangguan, W., \& Ji, D. (2014). A 3D canopy radiative transfer model for global climate modeling: Description, validation, and application. Journal of Climate, 27, 1168-1192. doi:10. 1175/JCLI-D-13-00155.1.

\section{Appendix. Detailed description of the methods}

\section{A.1. Vegetation map}

Vegetation reference points. To train and validate the vegetation map, we visually selected 187 points in the study area which were clearly within one vegetation type and estimated the radius for which each point was representative (point size in Figure 1b). As we were using a hand-held GPS with $\pm 3 \mathrm{~m}$ accuracy, we needed to validate the point locations in comparison with the orthomosaic. We removed points that lay outside the vegetation type in question (22 points) and shifted points which lay on the border of a vegetation patch (32 points). For 40 points, we reduced the size of the estimated radius because they intersected with other vegetation types on the orthomosaic. Half of the 
points were used for training of the vegetation classifier, the other half for validating the final map. We chose additional water training points based on the orthomosaic as they were difficult to access in the field.

Classification. We classified the vegetation based on the four image bands (RGB and NIR) as well as hue and saturation, which we calculated from the RGB image. We additionally used the entropy of the hue image as seventh input channel. For more robust mapping results, we reduced the image resolution to $15 \mathrm{~cm}$. The supervised classification was done with a maximum likelihood classifier (ENVI, Version 5.2). Based on field observations, we restricted low shrubs (S2) to areas close to rivers and floodplains in a post-processing step. In order to reduce the number of patches smaller than 4 pixels, we sequentially assigned those pixels to classes with a similar likelihood if that increased the patch size.

Classification accuracy. For comparison with other tundra maps, we aggregated the nine original classes to four classes as defined by the circumpolar Arctic vegetation map (Walker et al., 2005). These are tussock- sedge, dwarf shrub, moss tundra (G4), erect dwarf shrub tundra (S1-1, S1-2), low shrub tundra (S2), and sedge, moss, dwarf shrub wetland (W2-1, W2-2, W2-3, W2-4, and shallow water). For these four classes we obtained an overall accuracy of $65 \%$ and a Kappa coefficient of 0.53 using an equal amount of validation pixels per class. The best accuracy was achieved by including the lichen-rich shrub tundra (S1-2) in the tussock tundra class (G4). The map with four classes aggregated in this way had an overall accuracy of $74 \%$ and a Kappa coefficient of 0.65 .

The classification accuracy was lower than in other studies due to three main reasons. First, we were not able to collect water reference points in deep ponds or the river. We added additional points representing deep water to the training data based on visual inspection of the orthomosaic. Thus, the classifier was trained on points which included deep water bodies in the water class. Shallow water was mostly classified as waterlogged sedges (W2-4). As we did not add additional points to the validation data, the classification accuracy of 
water was only computed for shallow ponds which we were able to access in the field. Given the typically low vegetation density of waterlogged sedges and the strong background effects in both, waterlogged sedges and shallow water, this classification imprecision is not problematic and mainly due to suboptimal field sampling of reference points.

Second, the sub-classes dry sedges (W2-2) and peat moss (W2-3) were often misclassified because they appeared very similar on the orthomosaic. While peat moss occurred in both classes, the classes could be distinguished in the field based on the cover of sedges. However, dry sedges have a high cover of light-coloured standing dead leaves, which have a similar reflectance as peat moss areas, at least in the four spectral bands covered by the orthomosaic. The albedo of W2-2 and W2-3 was almost identical (Figure 5). These two sub-classes were mainly distinguished for modelling canopy transmittance and absorptance and should be merged in a vegetation map.

Third and most importantly, erect dwarf shrub tundra (S1-1 and S1-2) cannot be clearly distinguished from tussock sedge tundra (G4) by the classifier. This difficulty has been pointed out by Siewert et al. (2015) in a classification of a GeoEye-1 satellite image of the same field site. Several other studies do not distinguish, or do not have, tussock tundra (Lantz et al., 2010; Atkinson \& Treitz, 2012; Muster et al., 2012; Virtanen \& Ek, 2014). The similarity between lichen-rich shrubs and tussock tundra is a consequence of the similarity of the two classes in terms of species composition. The major difference is the presence of Eriophorum vaginatum, a tussock forming sedge. However, this sedge has a low leaf area and canopy height at the site (Table 2) and thus does not dominate the surface reflectance. As we modelled very similar albedo values for S1-2 and G4, landscape scale albedo is insensitive to misclassification between these classes.

The classification accuracy could potentially be improved by including the NDVI. However, we used the NDVI to spatially extrapolate model input variables and thus avoided circular reasoning by not including NDVI in the vegetation classification. A second potential classification input is microtopography. 
However, we used topography as input for the radiative transfer model and thus wanted to keep the vegetation classification independent of the topography. Spectrally similar vegetation classes could also have been avoided using an unsupervised classification approach (Atkinson \& Treitz, 2012). However, unsupervised classification of tundra areas does not necessarily yield homogeneous vegetation classes (Schneider et al., 2009). Furthermore, we collected input data for the radiative transfer model for specific vegetation classes in the field and thus were restricted to those for the modelling.

\section{A.2. Input variables for radiative transfer modelling}

Plant area index. We used different methods to measure green leaf area index (LAI) for shrubs and graminoids in the field in the peak growing seasons 2013 and 2014. Betula nana (S1-1) projected LAI and wood area index were measured non-destructively using $1 \mathrm{~m} \times 1 \mathrm{~m}$ point quadrat grids where we vertically lowered a needle at 81 points and recorded all contacts with leaves or wood (Juszak et al., 2016). We collected in total 25 measurements distributed over 10 plots within two growing seasons. We computed LAI by dividing projected LAI by the average point quadrat efficiency. The point quadrat efficiency was estimated in two destructive harvests to be 0.78 for $B$. nana leaves and 0.76 for B. nana wood. In case of LAI, this estimate contains the total one-sided LAI, while the wood area index is a projection of the cylindrical elements, approximately the product of branch diameter and length.

For estimating Eriophorum angustifolium (W2-1 and W2-2) LAI, we used an allometric approach, which involved counting leaves and destructively measuring single leaf areas (Juszak et al., 2016). For sub-class W2-1, we measured canopy height and counted all tillers and the number of green leaves per tiller on 16 squares of $100 \mathrm{~cm}^{2}$ on $1 \mathrm{~m}^{2}$. We collected in total 30 measurements distributed over 11 plots within two growing seasons. For sub-class W2-2, we measured canopy height, counted tillers and leaves on four plots of $50 \mathrm{~cm} \times 50 \mathrm{~cm}$. We combined the information of both E. angustifolium sub-classes with destructively measured leaf sizes. We measured the total standing dead leaf area of $E$. 
1114

1115

1116

1117

1118

1119

1120

1121

1122

angustifolium on three destructive plots of wet sedge tundra (W2-1) by weighing all standing dead leaves and scanning a subset.

Eriophorum vaginatum (G4) LAI was estimated on seven plots of $50 \mathrm{~cm} \times$ $50 \mathrm{~cm}$. We counted the number of leaves per plot and multiplied it by the average area of single leaves that was obtained from scanning.

We extrapolated the LAI spatially using the NDVI and an exponential function (Equation 2). To avoid unrealistically large LAI values, we reduced all LAI which were more than 1.5 times higher than the maximum observation to the maximum observed LAI. The parameters $a$ and $b$ are shown in Table A1 and the statistics of the modelled LAI per vegetation type in the strip transects in Table 2. We used literature values of LAI for low shrub tundra (S2) and waterlogged sedge tundra (W2-4). For low shrub tundra we took the minimum $(\mathrm{LAI}=0.77)$ and maximum $(\mathrm{LAI}=1.95)$ values from Imnavait creek water tracks, Alaska by Williams et al. (2006) and fitted them to the 0.05 and 0.95 quantiles of the NDVI data. The literature LAI values were consistent with other sources (Beringer et al., 2005). For Carex spp. dominated waterlogged sedge tundra we used LAI=0.4 (Carex spp. dominated wetland near Toolik, Alaska, Shaver \& Chapin (1991); McFadden et al. (2003)) as median and took the maximum value of LAI=0.65 (wet sedges without shrubs, S3, Imnavait creek, Alaska, Williams et al. (2006)) to fit to the 0.95 quantile.

We used linear regressions with observed LAI to spatially extrapolate the other input variables (Equation 3, Table A1). Due to the lack of observations for low shrub tundra wood area index, we used the same parameters that we obtained from the fit of dwarf birch leaf and wood area index (Table A1). We estimated standing dead leaf area and green leaf area index destructively at three plots of wet sedges (E. angustifolium, W2-1). Due to the limited number of observations, we forced the regression through zero assuming that standing dead leaves are always associated with plants which also have green leaves. We used the same parameters also for dry sedges (E. angustifolium, W2-2). 
Table A1: Parameters $a$ and $b$ for computing LAI from NDVI with an exponential equation (Equation 2) and parameters $p$ and $q$ for for computing other variables from LAI with a linear equation (Equation 3) for each vegetation type; canopy and standing dead leaf height in mm.

\begin{tabular}{|c|c|c|c|c|c|c|c|}
\hline Variable \Type & & $\mathrm{G} 4$ & $\mathrm{~S} 1-1$ & $\mathrm{~S} 2$ & W2-1 & W2-2 & $\mathrm{W} 2-4$ \\
\hline \multirow[t]{2}{*}{ LAI } & $a$ & 0.00002976 & 0.02618681 & 0.05929370 & 0.01425009 & 0.00202313 & 0.01523543 \\
\hline & $b$ & 12.6308 & 4.8927 & 4.4051 & 6.1931 & 8.8501 & 4.7804 \\
\hline \multirow{2}{*}{ Wood area index } & $p$ & 0 & 0.536 & 0.536 & 0 & 0 & 0 \\
\hline & $q$ & 0 & 0.439 & 0.439 & 0 & 0 & 0 \\
\hline \multirow{2}{*}{$\begin{array}{l}\text { Standing dead leaf } \\
\text { area index }\end{array}$} & $p$ & 0 & 0 & 0 & 1.16 & 1.16 & 0 \\
\hline & $q$ & 0 & 0 & 0 & 0 & 0 & 0 \\
\hline \multirow{2}{*}{ Canopy height } & $p$ & 0 & 7.21 & 80 & 16.7 & 8.51 & 16.7 \\
\hline & $q$ & 12.2 & 18.8 & 40 & 25.5 & 19.7 & 25.5 \\
\hline Standing dead leaf & $p$ & 0 & 0 & 0 & 8.13 & 8.13 & 0 \\
\hline height & $q$ & 0 & 0 & 0 & 11.3 & 11.3 & 0 \\
\hline
\end{tabular}

Canopy and standing dead leaf height. We used two different approaches to measure canopy height in the growing seasons 2013 and 2014. For dwarf birch (B. nana, S1-1) and wet sedges (E. angustifolium, W2-1) we measured canopy height at 25 points of a $1 \mathrm{~m} \times 1 \mathrm{~m}$ point quadrat grid at the same time and plots as our LAI estimate (Juszak et al., 2016). At the E. angustifolium plots, we also measured standing dead leaf height above the water or wet litter surface at the same points as canopy height. On the other hand, we measured canopy height of single individuals on six tussock sedge plots (E. vaginatum, G4) and five dry sedge plots (E. angustifolium, W2-2).

We extrapolated canopy height spatially for each type using a linear regression between canopy height and LAI measured at the same plots at the same time (Equation 3). For tussock tundra, the linear fit showed a negative relationship between LAI and canopy height for the six observations. Instead of a negative slope, we used a constant canopy height independent of the leaf area. For low shrub tundra we adjusted the parameters $p$ and $q$ in a way that the final canopy height varied between 1 and $2 \mathrm{~m}$ (Table 2), a range that we observed in the field. We used the parameters of E. angustifolium dominated wet sedge 


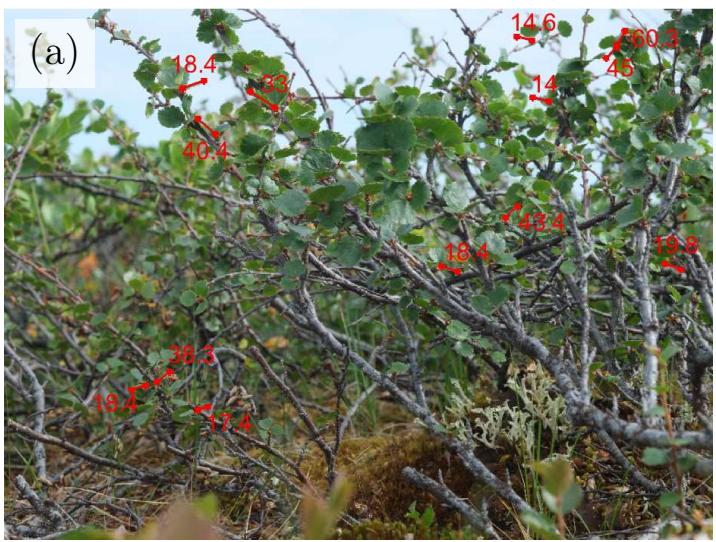
measurements covered only type W2-1.

\section{A.3. Input parameters for radiative transfer modelling} 1984; Strebel et al., 1985; Wang et al., 2007).

tundra (W2-1) also for Carex ssp. dominated waterlogged sedge tundra (W2-4, Table A1). We only observed a layer of standing dead leaves below E. angustifolium, in the vegetation types W2-1 and W2-2. Standing dead leaf height was related to LAI using the same parameters for both types although our field

Leaf and wood angle distribution. We measured the leaf angle distribution in three different ways depending on species and organ. For B. nana leaves, we used the method by Pisek et al. (2011). This method employs carefully levelled photography of the vegetation taken from all cardinal directions. In each image, we identified leaves which were perpendicular to the image plane. We marked these leaves in the image and calculated the leaf inclination angle (Leaf normal - nadir, Figure A1a). In total, we measured 1294 B. nana leaves. We fitted a beta function to the data to reduce the scatter (Figure A2a). Beta functions are commonly used for leaf inclination angle distributions (e.g. Goel \& Strebel,

Figure A1: Sample pictures used for measuring leaf angle distribution of (a) B. nana and (b) E. angustifolium; red numbers indicate the leaf inclination angle of a leaf or leaf segment.

1176 We had to modify the method by Pisek et al. (2011) for B. nana wood and E. 1177 angustifolium green and standing dead leaves as it was not possible to identify 
1178

1179

cylindrical or triangular objects perpendicular to the image plane. In this case, we marked all segments of green leaves, standing dead leaves, and wood that were visible on the images, even the segments pointing towards or away from the camera, in total more than 8000 per organ (Figure A1b). For leaves that were inclined towards or away from the camera, this raw data overestimated the leaf inclination angle. We corrected for this effect in three steps. First, we weighted the histograms of measured inclination angles by the length of each identified segment. We did that for each azimuth view direction separately and then took the mean of all probability distributions as we did not identify an equal amount of segments in each view direction. Second, we converted the observed, projected leaf inclination angle distribution to the real inclination angle distribution assuming a random distribution of leaf azimuth angles. This step involved binning the leaf inclination angles and computing weights for each bin which describe, how much of which original leaf angle has contributed to this bin given random azimuth angles. The real leaf angle distribution was computed by solving a linear system of equations with the projected leaf angle distribution and the weights of all bins. Third, we corrected for the fact that leaves appeared shorter on the images if they were not perpendicular to the image plane. Finally, we fitted a beta function to the data (Figure A2b-d) in the same way as for B. nana leaves.

For E. vaginatum and Salix pulchra, we manually measured the leaf inclination angles of 21 and 39 leaves, respectively. As the number of measured leaves was small, we did not fit a beta function to the data but selected the best fitting standard leaf angle distributions, 'erectophil' for E. vaginatum and 'uniform' for S. pulchra (Figure A2e, f) (de Wit, 1965).

Leaf and wood optical properties. We measured optical properties of plant organs in the field using an Ocean Optics SpectroClip probe in the peak growing seasons 2013 and 2014 (Figure A3). The probe features two integrating spheres of about $3.5 \mathrm{~cm}$ diameter, one for the reflectance and the second for the transmittance of the sample. The sample is fitted between the two spheres 


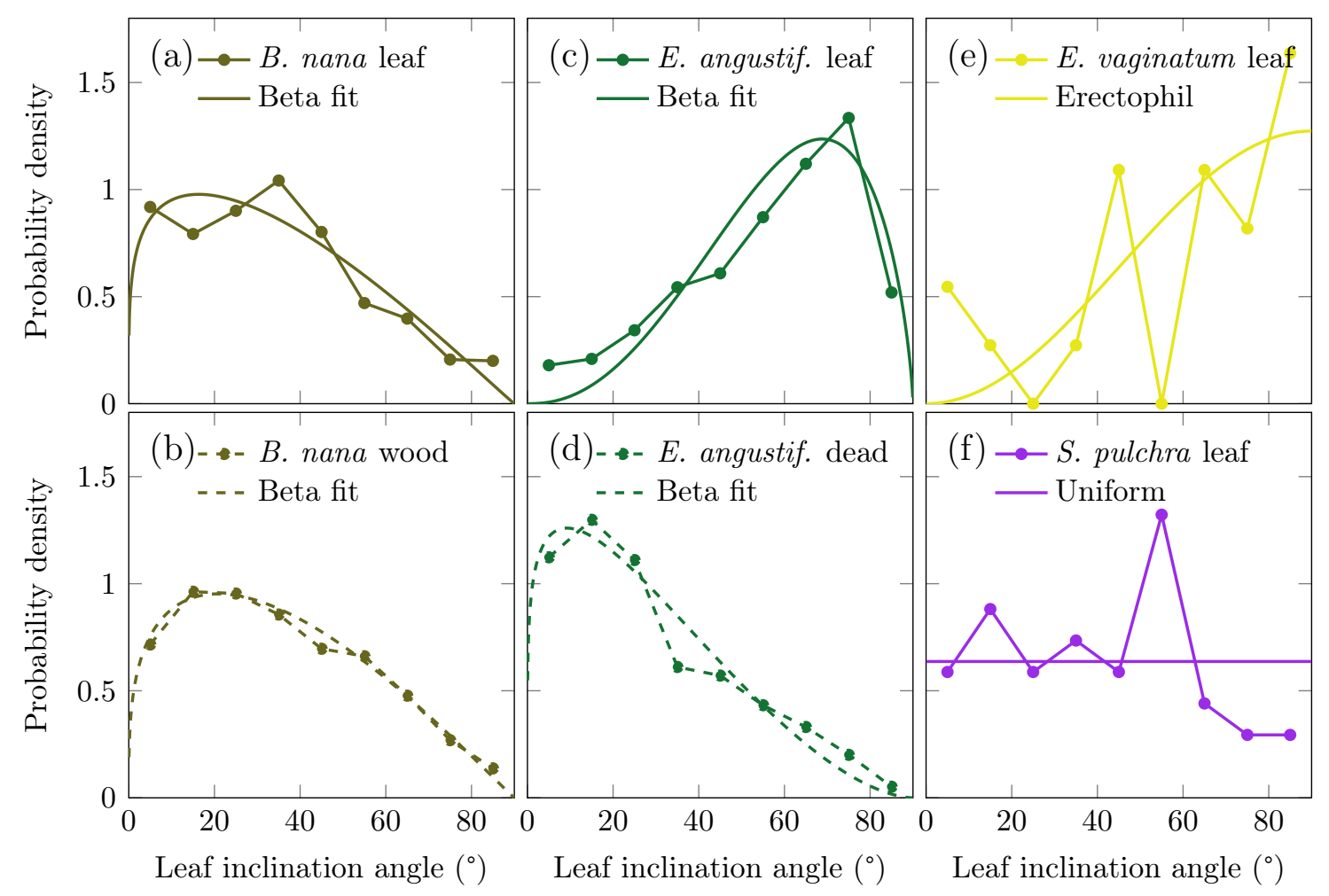

Figure A2: Probability density (bin width: $1 \mathrm{rad}=57.3^{\circ}$ ) of measured green leaf, standing dead leaf, and wood inclination angle distributions and fitted functions of (a) Betula nana leaves, (b) B. nana wood, (c) Eriophorum angustifolium green leaves, (d) E. angustifolium standing dead leaves, (e) Eriophorum vaginatum leaves, and (f) Salix pulchra leaves. 
1208

with a measurement area of $5 \mathrm{~mm}$ diameter. In addition to our measurements of samples, we regularly took reference measurements with a $99 \%$ and a $50 \%$ reflectance standard and without sample. The integrating spheres were too small in comparison to the sample size to provide data without correction for multiple interactions between light and sample (Jacquez \& Kuppenheim, 1955). Thus we did a first-order correction of the raw reflectance and transmittance measurements. We estimated the fraction of light that interacted twice with the sample before being recorded using a comparison between the readings of the $99 \%$ standard and the $50 \%$ standard. Although we could only calibrate this fraction for non-transmitting samples, we used the same value also for the correction of the transmittance signal. The correction of the samples transmittance involved assuming equal reflectance and transmittance of both leaf sides. We tested the correction for leaves which we measured with the standard procedure, including transmittance, and on a black background.

E. vaginatum leaves were too thin to be measured with the SpectroClip probe in the standard procedure. Therefore, we fixed multiple leaves next to each other on a sample holder. As all leaves together covered the measurement area, we could use the reflectance measurement without further correction. However, for the transmittance measurement, we had to adjust for the reduced transmittance due to the holder. We estimated the $E$. vaginatum leaf transmittance $(T)$ from the corrected transmittance measurement $\left(T_{\text {measured }}\right)$ and the transmittance of the empty holder ( $T_{\text {empty }}$ holder $)$ :

$$
T=\frac{T_{\text {measured }}}{T_{\text {empty holder }}^{2}}
$$



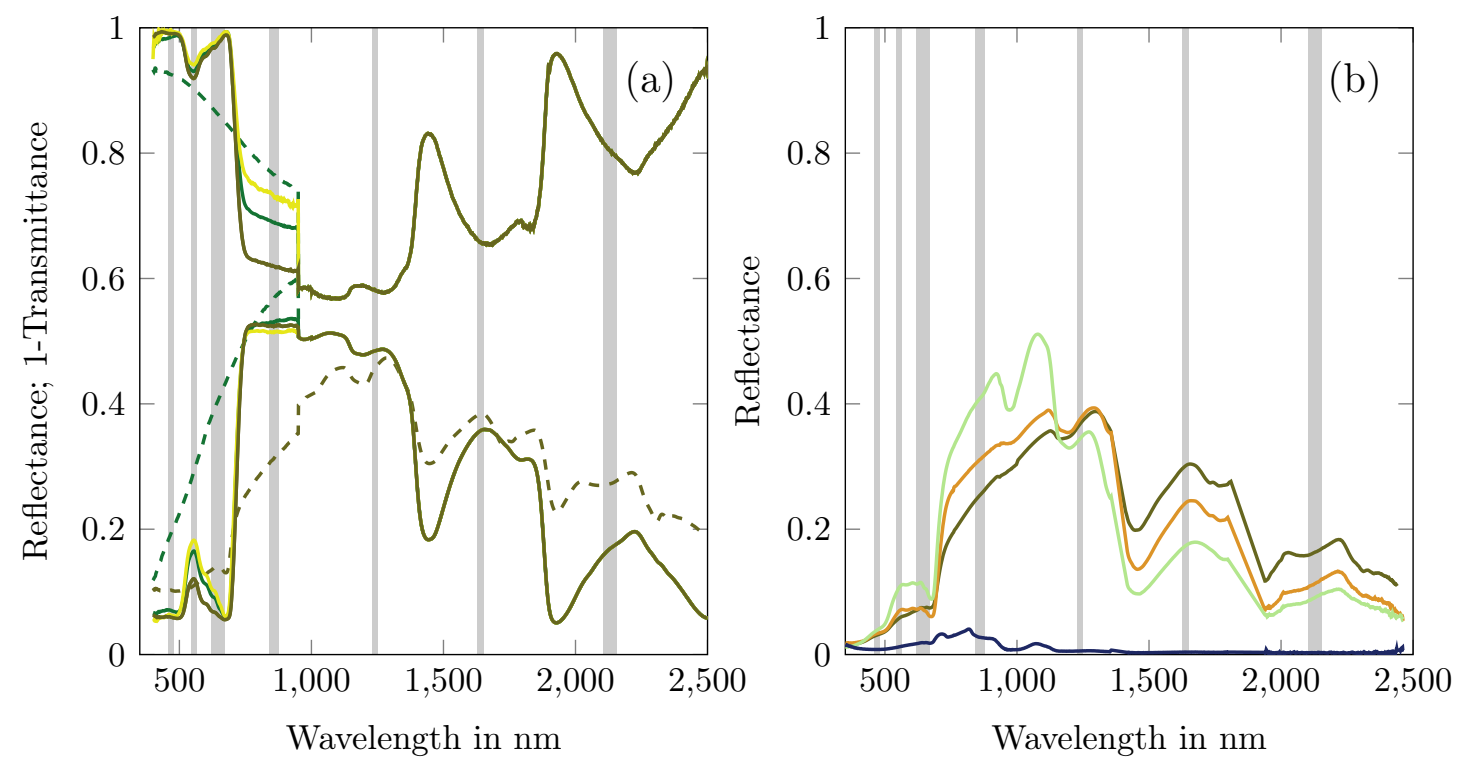

- B. nana leaves

- - B. nana wood

— S1-1 background

- E. angustifolium leaves

- - - E. angustifolium standing dead $\mathrm{S} 1-2$

W2-3

E. vaginatum leaves

Figure A3: (a) Upper face reflectance (bottom half) and transmittance (top half) of the major species (bottom face reflectance not shown for clarity) and (b) background reflectance; the grey lines indicate the MODIS bands 1-7 used for modelling. 